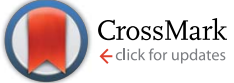

Cite this: J. Anal. At. Spectrom., 2015, 30, 1017

Received 20th March 2015

Accepted 20th March 2015

DOI: 10.1039/c5ja90017d

www.rsc.org/jaas

\section{Atomic spectrometry update: review of advances in atomic spectrometry and related techniques}

\author{
E. Hywel Evans, ${ }^{\text {*a }}$ Jorge Pisonero, ${ }^{b}$ Clare M. M. Smith ${ }^{c}$ and Rex N. Taylor $^{d}$
}

$\begin{array}{ll}\text { 1 } & \text { Sample introduction } \\ \text { 1.1 } & \text { Liquids } \\ \text { 1.1.1 } & \text { Sample pre-treatment } \\ \text { 1.1.1.1 } & \text { Solid phase extraction } \\ \text { 1.1.1.2 } & \text { Liquid phase extraction } \\ \text { 1.1.1.3 } & \text { Elemental tagging } \\ \text { 1.1.2 } & \text { Nebulisation } \\ \text { 1.2 } & \text { Vapour generation } \\ \text { 1.3 } & \text { Solids } \\ \text { 1.3.1 } & \text { Direct methods } \\ \text { 1.3.1.1 } & \text { Glow discharge } \\ \text { 1.3.1.2 } & \text { Secondary ion mass spectrometry } \\ \text { 1.3.2 } & \text { Indirect methods } \\ \text { 1.3.2.1 } & \text { Laser ablation } \\ 2 & \text { Instrumentation, Fundamentals and Chemometrics } \\ \text { 2.1 } & \text { Instrumentation } \\ \text { 2.2 } & \text { Fundamentals } \\ \text { 2.2.1 } & \text { Fundamental constants } \\ \text { 2.2.2 } & \text { Diagnostics } \\ \text { 2.2.3 } & \text { Interferences } \\ 2.3 & \text { Chemometrics } \\ 3 & \text { Laser-based atomic spectrometry } \\ \text { 3.1 } & \text { LIBS } \\ \text { 3.1.1 } & \text { Fundamental studies } \\ \text { 3.1.2 } & \text { Instrumentation } \\ \text { 3.1.3 } & \text { Novel LIBS approaches } \\ \text { 3.2 } & \text { Laser atomic absorption spectroscopy (LAAS) } \\ \text { 3.3 } & \text { Cavity Ringdown Spectroscopy (CRDS) } \\ \text { 3.4 } & \text { Laser-induced fluorescence (LIF) } \\ \text { 4 } & \text { Isotope analysis } \\ \text { 4.1 } & \text { Instrumental developments } \\ \text { 4.2 } & \text { Radionuclide isotope ratio analysis } \\ & \end{array}$

${ }^{a}$ School of Geography, Earth, and Environmental Sciences, University of Plymouth, Drake Circus, Plymouth, PL4 8AA, UK.E-mail: hevans@plymouth.ac.uk

${ }^{b}$ University of Oviedo, Faculty of Science, Department of Physics, c/Calvo Sotelo $s / n$, 33006 Oviedo, Spain

${ }^{c}$ St. Ambrose High School, Blair Road, Coatbridge, Lanarkshire, ML5 2EW, UK

${ }^{d}$ Ocean and Earth Science, University of Southampton, NOC, Southampton, SO14 3ZH, $U K$

\author{
4.3 Radiogenic isotope measurement \\ 4.4 Stable isotope systematics \\ $5 \quad$ Glossary \\ 6 References
}

This review covers developments in 'Atomic Spectrometry'. It covers atomic emission, absorption, fluorescence and mass spectrometry, but excludes material on speciation and coupled techniques which is included in a separate review. It should be read in conjunction with the previous review ${ }^{1}$ and the other related reviews in the series. ${ }^{2-6}$ A critical approach to the selection of material has been adopted, with only novel developments in instrumentation, techniques and methodology being included. One of the major developments which has gained traction over the past few years is the use of elemental tagging for the relative and absolute quantification of biological molecules using ICP-MS. This has advanced to the stage where it is now routinely used as an assay technique. A number of variations on this approach have also been developed in order to improve sensitivity by amplification of the signal, particularly for polynucleotide analysis. Single particle analysis by ICP-MS and ICP-AES has been used to gain some valuable insights into the atomisation and ionisation processes occurring in the ICP, as well as providing a means of quantification of nanoparticles. The dielectric barrier discharge (DBD) has attracted interest as a compact, low-power, microplasma source for $M S$ and $A E S$, following the trend for all things miniature, as well as for direct analysis of liquids. The use of MC-ICP-MS is the driver behind advances in the isotope ratio analysis of natural stable isotopes of metallic elements. Double spiking is an expanding method to neutralise instrumental and procedural mass-dependent fractionation in both stable and radiogenic isotope systems. An overlap is emerging between the measurement of uranium isotope variation in natural systems and the $U$ isotope determination for the nuclear forensic or monitoring/safeguarding fields. Coincident analytical techniques between these fields is likely to produce useful advances in the analysis of nuclear materials. 


\section{Sample introduction}

\subsection{Liquids}

\subsubsection{Sample pre-treatment}

1.1.1.1 Solid phase extraction. Sample pre-concentration using this approach has been around for a long time, so there is very little of obvious novelty. Over the last few years methods involving automation, MNPs, ILs and micelles have been the most often reported novel developments, as a recent review (69 references) by Lum et al., ${ }^{7}$ focusing on clinical samples, details. One of their conclusions is that micro-extraction and automated methods are becoming more important, particularly in the clinical field where high throughput of small samples is a requirement for routine diagnostic tests. Micro-extraction (namely SPME) methods were reviewed ( 82 references) by Deng et al. ${ }^{8}$ in combination with MS methods of detection, including a short section on coupling with ICP-MS.

Building on their previous work, Su et al. ${ }^{9}$ have incorporated non-functionalised PVC tubing as the SPE medium for online analysis of living rat brain microdialysates using ICP-MS. The labon-a-valve (LOV) system was designed to operate by taking segmented flow samples of microdialysate and adjusting the $\mathrm{pH}$ by $1+3$ dilution with $40 \mathrm{mM}$ phosphate buffer to optimise absorption of metal ions onto orange/green PVC peristaltic tubing (48 $\mathrm{cm}$ long $\times 0.38 \mathrm{~mm}$ i.d.). Elution was achieved with $0.2 \%$ nitric acid. The flow-rate was only $20 \mu \mathrm{L} \mathrm{min}{ }^{-1}$ so a microflow nebuliser was necessary for ICP-MS detection. In this way, using segmented flow preconcentration, temporal changes in $\mathrm{Co}, \mathrm{Cu}, \mathrm{Mn}, \mathrm{Ni}$ and $\mathrm{Zn}$ concentration could be measured in vivo at sub $\mu \mathrm{g} \mathrm{L}^{-1}$ levels. This reviewer must confess to being somewhat surprised by the efficacy of PVC tubing as an SPE medium, however, the authors obtained spike recoveries of between 88 and $107 \%$. In a second paper $^{10}$ the same authors adopted a similar approach, but using a minicolumn packed with PVC beads instead of bare tubing. They used the system to monitor the permeability of the blood-brain barrier to MMA, DMA, molybdate and MeHg.

Magnetic nanoparticles (MNPs) have been widely used as substrates for SPE due to the ease with which they can be used to separate the analyte from the matrix after preconcentration. The field was reviewed ( 88 references) by Wierucka and Biziuk ${ }^{\mathbf{1 1}}$ who outlined the process and tabulated applications with respect to analyte, MNP coating, technique, LOD etc. A variety of substances have been used to coat MNPs (e.g. silica, alumina, manganese oxide graphene, divinylbenzene, polyamidoamines, surfactants and IPs). In this vein, Najafi et al. ${ }^{12}$ coated an MNP with an IIP to act as an SPE substrate for the determination of $\mathrm{Hg}$. The $\mathrm{Fe}_{3} \mathrm{O}_{4}$ MNPs were first vinyl functionalised by reaction with 3-vinyletriethoxy silane, then imprinted by reaction with $\mathrm{Hg}(\mathrm{V}-\mathrm{Pic})_{2} \cdot 2 \mathrm{NO}_{3}$, ethylene glycol dimethylacrylate and azobisisobutyronitrile. Then, $0.1 \mathrm{~mol} \mathrm{~L}^{-1} \mathrm{HCl}$ and $0.1 \mathrm{~mol} \mathrm{~L}^{-1}$ EDTA was used to remove the $\mathrm{Hg}$ ions, leaving the IIP template. A variety of fish digests were analysed by preconcentration and matrix separation using the IIP-MNPs to yield recoveries of between 98 and $102 \%$ and an LOD of $0.03 \mathrm{ng} \mathrm{mL}^{-1}$. There are many other reports of SPE using MNPs, but this is a nice example of combining two established technologies in a novel way.

1.1.1.2 Liquid phase extraction. There were practically no novel developments in this area over the period of the review. The only LPE method which has recently attracted new research output is the use of ionic liquids (ILs). This was reviewed (165 references) by Martinis et al., ${ }^{\mathbf{1 3}}$ with a particular focus on trace element analysis. The review is cross-referenced in tables with respect to analyte, sample, technique, IL used, LOD etc., making the information easy to find. They concluded that ILs are often (but not always) greener alternatives to traditional methods using organic solvents, and that there is scope for improving selectivity by functionalisation.

1.1.1.3 Elemental tagging. Over the last few years the use of elemental tagging for the relative and absolute quantification of biological molecules using ICP-MS has advanced to the stage where it is now routinely used as an assay technique. Several approaches have been adopted but all share the same basic premise: either the molecule is quantified by direct determination, usually due to the presence of a metal, $\mathrm{S}$ or $\mathrm{P}$ in its structure; or it is tagged with a metal-containing conjugate molecule which allows determination by ICP-MS. A number of variations on this approach have also been developed in order to improve sensitivity by amplification of the signal.

The quantification of polynucleotides particularly lends itself to this type of analysis. For example, Bruckner et $a l .{ }^{14}$ developed a ligation-mediated amplification method for determination of DNA. The tagging reagent was a maleimide-functionalised chelating agent (1,4,7,10-tetraazacyclo-dodecane $N, N^{\prime}, N^{\prime \prime}, N^{\prime \prime \prime}$ tetra acetic acid, DOTA) complexed with Tb (DOTA-mal-Tb). This reporter molecule is widely used to label oligonucleotides complementary to target DNA sequences, the so-called reporter probe. The target DNA was hybridised with both the reporter probe and another probe, called the capture probe, which had been labelled with biotin. Separation of the hybridised target from excess reagent was then effected in wells coated with streptavidin, by means of the streptavidin-biotin affinity, and subsequent washing. The target complexes were eluted by denaturing in hot nitric acid (or alternatively by using a restriction enzyme) and quantified using ICP-MS to achieve an LOD of $7.2 \mathrm{fmol}$. This basic assay was modified to include an amplification step in which the reporter and capture probes were ligated together after hybridisation with the target DNA, using DNA ligase, to form a single strand. This strand was detached from the original target DNA by raising the temperature to $94{ }^{\circ} \mathrm{C}$. The temperature was then lowered to $37{ }^{\circ} \mathrm{C}$ and the cycle repeated sixteen times, resulting in 6000-fold amplification of the original target DNA sequence in a ligase chain reaction. Subsequent separation and quantification was as before, resulting in an LOD of 2.6 amol, equivalent to $1.6 \times 10^{6}$ copies of the target DNA.

Luo et $a .^{15}$ developed another approach like this, except using magnetic nanoparticle (MNP) labelled capture probes to effect separation, and reporter probes labelled with a variety of lanthanides to enable a multiplexed assay. This resulted in method detection limits of 28, 48 and 19 amol for the HIV/AIDS viral sequences HIV, HAV and HBV respectively, with recoveries 
of between 94.2 to $109.1 \%$. They also investigated the rolling circle amplification (RCA) method to improve sensitivity. This works by creating a long strand of DNA attached to the original MNP-labelled target sequence, containing multiple 20 base pair (bp) repeat sequences. Lanthanide labelled reporter probes with complementary 20 bp sequences can then be hybridised, separated from excess reagent, and quantified by ICP-MS. Using this method, they achieved 190-fold signal enhancement for ${ }^{165} \mathrm{Ho}$, suggesting that 190 rounds were performed after $2 \mathrm{~h}$ of amplification. The MDL for HBV was determined to be $90 \mathrm{zmol}$. A very similar approach, using RCA and MNP capture probes, was developed by He et al., ${ }^{\mathbf{1 6}}$ except that they used reporter probes labelled with $\mathrm{Au}$ nanoparticles rather than DOTA-Ln complexes. They achieved an LOD of $0.1 \mathrm{fmol} \mathrm{L}^{-1}$ for a synthetic oligonucleotide. Two other papers ${ }^{17,18}$ describe variations on the aforementioned methods, but without the amplification step. The important point to note is that the amplification step has been the major novel development to emerge since last year's review. This should result in levels of detection which are useful for clinical diagnosis.

It is also necessary to separate the hybridised target molecule from excess reagents. This is usually achieved by using a capture probe, as described in the aforementioned articles. However, this is not possible for the determination of short strands of microRNA, which are only 20-24 nucleotides long, because it is not possible to attach both a capture and reporter probes to such short lengths with high specificity. De Bang et al. ${ }^{19}$ got around this problem by separating the miRNA targets using gel electrophoresis. They then used a northern blotting procedure to hybridise the separated fragments with complementary DOTA-mal-Ln labelled DNA reporter probes which were an exact match for the target RNA sequences. This yielded LODs of $0.12 \mathrm{ng}(18 \mathrm{fmol})$ and $0.01 \mathrm{ng}(1.5 \mathrm{fmol})$ of miRNA, using LA-ICPMS and radioactive detection $\left({ }^{32} \mathrm{P}\right)$ respectively. The authors speculated that this could be improved by better separation of the excess Ln reagents to eliminate background noise; though evidently this technique would also benefit from an amplification step.

Quantification of proteins is possible either via determination of an endogenous element such as S, P, Fe or Se or by labelling with an elemental tag. Further, the use of IDA offers great accuracy and precision but requires that isotopically labelled analogues of the target molecules are available. This can be achieved either by synthesis of an isotopically enriched analogue of the protein, or by labelling with an isotopically enriched tag.

Schwarz et al. ${ }^{20}$ have reviewed (90 references) the use of DOTA as a chelating complex for labelling proteins and peptides with metals for the purpose of quantification. They usefully cover the main chemistries available for conjugation of DOTA with proteins, attachment of antibodies for immunoassays, and chelation of the lanthanides with DOTA. They also cover separation and purification steps and the measurement process using ICP-MS, including LA. For anyone wanting to get up to speed on this particular application this is a very concise and useful review. Another review (88 references) by $\mathrm{He}$ et $a .^{21}$ throws its net wider by covering applications of HPLC-ICP-MS using organo-mercury, iodine, ferrocene and metal-chelate complexes. This is probably less useful for the researcher wanting to learn how to apply the technique than the former review because it suffers from being neither comprehensive nor detailed enough. A third review by Campanella and Bramanti ${ }^{22}$ covers both detection of endogenous metals covalently bound to proteins and elemental labelling. With 248 references, this is clearly the most comprehensive of the three reviews and overviews the different types of chromatographic methods for protein separation, and methods of detection including AAS, ICP-MS, ICP-OES and AFS. Sections are devoted to the determination of proteins containing endogenous $\mathrm{Cu}, \mathrm{Fe}$, Se and metallothioneins, and labelling using $\mathrm{Hg}$, I, metallocenes and metal-chelate complexes. The literature is cross-referenced in tables according to 'sample type', 'labelling tag', 'separation technique' and 'detector'.

If IDA is to be used for quantification of a protein containing an endogenous metal then spiking with an enriched isotope can be performed in one of two ways: either using an inorganic salt; or a synthetically produced isotopically enriched analogue of the target molecule. If the method involves a separation step, such as in LC-ICP-MS, these approaches are referred to a 'species non specific' and 'species specific' IDA respectively. Konz et $a l .{ }^{23}$ synthesised isotopically enriched ${ }^{57} \mathrm{Fe}$-ferritin by incorporation of $\left(\mathrm{NH}_{4}\right)_{2}{ }^{57} \mathrm{Fe}(\mathrm{II})\left(\mathrm{SO}_{4}\right)_{2}$ into apo-ferritin, resulting in $\mathrm{Fe}$ : ferritin ratios of about $2200 \mathrm{Fe}$ atoms per ferritin molecule with $92.6 \%$ abundance of ${ }^{57} \mathrm{Fe}$. Analysis by TEM indicated that $\mathrm{Fe}$ was incorporated within the protein core as an iron oxide nanoparticle with a diameter of $6.8 \mathrm{~nm}$. Species specific IDA of the standards was performed using SEC-ICP-MS and post-column IDA of S. One of the problems with this approach is that the $\mathrm{Fe}$ : ferritin ratio varies, so the same group investigated an alternative approach. ${ }^{24}$ This involved a sandwich immunoassay with electrogenerated chemiluminescence (ECL) and ICPMS detection to establish the Fe-ferritin : Ru stoichiometry (1:23), which was required for accurate quantitation. Ferritin was tagged with antibody- $\left[\mathrm{Ru}(\mathrm{bpy})_{3}\right]^{2+}$ reporter and antibodybiotin-streptavidin-MNP capture probes. Detection of the $\left[\mathrm{Ru}(\mathrm{bpy})_{3}\right]^{2}$ moiety was then performed by both ECL and IDA-FIICP-MS using ${ }^{99} \mathrm{Ru}$ as the spike. The method was validated by determination of NIBSC 94/572 ferritin reference material at pmol L ${ }^{-1}$ levels, with between 85 and $95 \%$ recovery.

The preceding discussion well illustrates the problem of not knowing the exact metal:protein stoichiometry in a protein containing an endogenous metal, and the solution now adopted by many workers of using elemental tags for quantification. The tagging approach is attractive because it is based on available technology which has been adapted for this purpose. Liang et al. ${ }^{25}$ have developed a 'click chemistry' approach to simultaneously measure the activity of, and quantify, the enzyme P450 3A4 (CYP3A4). A hexynylated 17 $\alpha$-ethynylestradiol activity-based probe was used to label the CYP3A4 molecule, and also conjugated, via an alkyne group, with an azido-DOTA-Eu complex. In this way, the activity of the enzyme could be assayed via the activity probe, and quantification performed by species unspecific ID-ICP-MS using ${ }^{153} \mathrm{Eu}$, to achieve an LOD of $20.3 \mathrm{fmol}$. The method was validated by determination of CYP3A4 in human 
liver microsome samples to be $1.04 \pm 0.05 \mu \mathrm{M}$ compared with the value of $1 \mu \mathrm{M}$ given by the producer.

El-Khatib et al. ${ }^{26}$ developed an Ln-DOTA-dimedone tagging reagent which is specific for peptides and proteins containing sulfenic acid (SA). They also used a lanthanide labelled metal coded affinity tag, with an iodoacetamide conjugation group specific for thiols, (Ln-MeCAT-IA) in a dual labelling strategy for absolute and relative quantification of the proteins using ICP-MS. They proposed that this could be a useful method for the direct comparison of thiol groups and SA for monitoring oxidation in biological samples in the pmol to amol range. Yan et $a .^{27}$ have used an element-tagged photo-cleavable biotinylated chemical 'hub' for absolute quantification and identification of proteins by ICP-MS and ES-MS. The reagent in question comprised: a sulfonyl fluoride guiding group to imbue specificity towards the hydroxyl group of serine residues in serine proteases; Eu-DOTA for quantification by ICP-MS; biotin for separation on streptavidin-coated beads; and a photocleavable $o$-nitrobenzyl ether linker to release the captured protein for ES-MS identification. Clearly, there are an immense number of variations of the tagging techniques which have yet to be reported.

Many of the tagging methods used for quantification of biological molecules are based on immunoassays, a topic which has been comprehensively reviewed by Liu et al. ${ }^{28}$ They covered the basic theory of immunoassay and the advantages of using metal tags in conjunction with ICP-MS detection. In particular they reviewed the use of nanoparticles and polymeric chelating tags used for signal amplification, the multiplexing advantage, and its use in cell cytometry. The review has approximately 200 references and applications tabulated with respect to analyte, immunoreaction type, elemental tag and LOD. Another review (94 references) by Bjornson et al. ${ }^{29}$ focussed on applications of cell cytometry using metal tagging in the clinical area. They concluded that improvements in sensitivity, sample flow rate and recovery are still required, but multi-dimensional, singlecell mass cytometry should have a dramatic effect on drug development and therapies.

An immunoassay method for glycoproteins has been developed by Peng et al. ${ }^{30}$ They used Con A, a glucose and mannose selective MNP-lectin, to capture haptoglobin (HP), hemopexin (HPX) and ovalbumin (OVA), which were then immune-labelled with antibody-polymer multielement tags $(\mathrm{Cd}, \mathrm{Hg}, \mathrm{Pb})$ for signal amplification and multiplexed detection. Separation of the MNP-immuno-complex from excess reagent was achieved in a magnetic field, then quantified using ICP-MS. LODs of 0.032, 0.027 and $0.13 \mathrm{ng} \mathrm{mL}^{-1}$ were obtained for HP, HPX and OVA respectively. The method was used to determine glycoproteins in real human serum with recoveries of over 97\%. An immunoassay for Jurkat $\mathrm{T}$ was developed by Zhang et al. ${ }^{31}$ using MNPantiCD3 capture probes, Au-NP-antiCD2 reporter probes, and ICP-MS detection. By taking advantage of the amplifying effect of the Au-NP the LOD was 86 cells, which is comparable with electrochemical detection but faster. It is clear that the use of elemental tagging immunoassays with ICP-MS detection has exploded over the review period, and is now competing with conventional molecular mass spectrometry in many biological and clinical applications, which is a great advance for the technology and probably not foreseen when ICP-MS was being developed. Numerous other applications using the same basic format have been published for the quantification of antibodies, ${ }^{32}$ HIV-1 p24 antigen, ${ }^{33}$ cytochromes, ${ }^{34}$ and various biomarkers. ${ }^{35,36}$

1.1.2 Nebulisation. A droplet microfluidic sample introduction system for ICP-MS was described by Verboket et al. ${ }^{37}$ The disposable microfluidic chip generated droplets of an aqueous sample in a stream of perfluorohexane ( $\mathrm{PFH})$, which was also used to eject them as a liquid jet. The aqueous droplets remained intact during the ejection and were transported into the ICP with $>50 \%$ efficiency. The system could generate highly monodisperse droplets in the size range of $40-60 \mu \mathrm{m}$ at frequencies from 90 to $300 \mathrm{~Hz}$. These droplets produced signals with an RSD comparable to that achieved with a commercial droplet dispenser.

Single particle inductively coupled plasma mass spectrometry ( $s p-I C P-M S)$ is an emergent method for detecting, characterising, and quantifying nanoparticles. An introduction to the technique is provided by Laborda et al. ${ }^{38}$ Despite the somewhat limited number of published applications to date, the relatively simple instrumental requirements, the low detection levels attainable, and the possibility to detect both the presence of dissolved and particulate forms of an element make this methodology very promising in the nanoscience areas. This is reflected in the number of research papers in the area that have been published during the period covered by this review. Linsinger et al. reported on the results of an international intercomparison of particle-size determination by sp-ICP-MS. ${ }^{39}$ Concentrated monodisperse Ag nanoparticle suspensions with particle diameters of 20,40 and $100 \mathrm{~nm}$ and a blank solution were sent to 23 laboratories in Europe, the USA and Canada. Laboratories prepared eight nanoparticle preparations in two food simulants (distilled water; 10\% ethanol) and reported median particle size, $\mathrm{Ag}$ particle mass concentration and $\mathrm{Ag}$ particle number concentrations. Average repeatability $(r)$ and reproducibility $(R)$ standard deviation for the median particle diameter were 1 and $14 \mathrm{~nm}$, respectively. Relative precision was poorer for Ag particle number concentrations (RSD $(r)=11 \%$; $\operatorname{RSD}(R)=78 \%)$. The improvements on the method were identified as software tools for evaluation, hardware options for shorter dwell times, calibration standards for determining nebuliser efficiency and further experience by laboratories. However, the results of this study certainly demonstrate the suitability of sp-ICP-MS for the detection and quantification of certain kinds of nanoparticles. Liu et al. carried out a study on sp-ICP-MS for Au nanoparticles from 10 to $200 \mathrm{~nm} .^{40}$ The study concluded that a major improvement in quality of the data results from optimisation of dwell time, with the optimal dwell time (limiting split particle events, particle coincidences and false positives) being $10 \mathrm{~ms}$. Transient features of single particle events were temporally resolved on a quadrupole ICP-MS system using a sufficiently short dwell time $(0.1 \mathrm{~ms})$. The linear dynamic size range of the ICP-MS system under standard (highest) sensitivity conditions was 10 to $70 \mathrm{~nm}$ but could be further extended to $200 \mathrm{~nm}$ by operating in less sensitive 
modes. Hineman and Stephan also investigated the effect of dwell time on sp-ICP-MS data acquisition quality. ${ }^{41}$ They noted that nanoparticle events in the plasma are less than $0.5 \mathrm{~ms}$ in duration whilst current conventional quadrupole-based ICP-MS instruments are limited to instrument dwell times in the millisecond range and have data acquisition overheads that adversely affects data quality. Novel instrument settings and data processing techniques were used to explore the benefits of continuous data acquisition rates as fast as $105 \mathrm{~Hz}$ (or $10 \mathrm{~ms}$ dwell times). The authors provided data on the different effects that data acquisition rate has on the quality of data that can be obtained by sp-ICP-MS. The effect of varying the dwell time and its influence on particle integration, particle counting, particle sizing, and background signal was discussed. The relatively poor accuracy obtained in measurement of size and number concentration by sp-ICP-MS was addressed by Tuoriniemi et al. $^{42}$ The relative contributions of different types of noise to the overall uncertainty during sp-ICP-MS measurements of Ag and $\mathrm{Au}$ nanoparticle dispersions were quantified showing that the accuracy of sp-ICP-MS is mainly limited by the uncertainty in nebulisation efficiency. This uncertainty was improved by correcting for analyte partitioning effects during nebulisation. The calculated $\mathrm{Ag}$ and $\mathrm{Au}$ nanoparticle sizes were in close agreement with sizes determined by SEM. The duration of the particle events was measured, which allowed correction for incomplete particle events and detector dead time, and determination of the effective dwell time for particle counting. The number concentration measured with sp-ICP-MS agreed with that measured by counting particles deposited on filters, and calculated from the mass concentration of the analyte.

\subsection{Vapour generation}

Pohl et $a .^{43}$ reviewed (41 references) progress in the vapour generation of transition metals with tetrahydroborate. The review contains sections on manifolds, gas-liquid separators, reaction conditions, interferences and analytical applications, cross-referenced in tables in each of these categories. The authors concluded that chemical vapour generation (CVG) of transition metals is more problematical than traditional HG due to the sensitivity of the chemistries involved and instability of the volatile species. Slachcinski ${ }^{44}$ reviewed (248 references) CVG with different combinations of sample introduction systems with plasma AES and MS. This included traditional modes with nebulisers, electrothermal preconcentration, slurry sampling, capillary electrophoresis, electrochemical and photochemical vapour generation. Numerous tables crossreference with analyte, detection method, interference etc.

Several novel methods of $C V G$ have been reported over the period of the review. Lopez-Molinera et $a l .{ }^{45}$ have investigated the kinetics of the generation of volatile halides of $\mathrm{As}^{\mathrm{III}}, \mathrm{Ge}^{\mathrm{IV}}$, $\mathrm{Sb}^{\mathrm{III}-\mathrm{V}}$ and $\mathrm{Se}^{\mathrm{IV}-\mathrm{VI}}$. The method utilised concentrated sulfuric acid to generate volatile fluoride, chloride and bromide species on injection of solutions of analyte and halide. The most rapidly evolved species were $\mathrm{As}^{\mathrm{III}}$ chloride, $\mathrm{Se}^{\mathrm{VI}}$ bromide and $\mathrm{Sb}^{\mathrm{V}}$ bromide, with appearance times of $<1.0 \mathrm{~min}$. Some dependency on halide composition was noted, with chloride species vaporised at medium to high chloride concentrations whereas bromide and fluoride species required low halide concentrations. The sensitivity of ICP-OES detection was dependent on the speed of the reaction and the relative bond strengths of the different halides. Species formed by $\mathrm{Ge}^{\mathrm{IV}}$ and $\mathrm{As}^{\mathrm{III}}$ with chloride, and $\mathrm{Sb}^{\mathrm{V}}$ and $\mathrm{Se}^{\mathrm{VI}}$ with bromide exhibited the greatest analytical potential. This type of reaction was made use of in a completely opposite sense by Reddy et al. ${ }^{46}$ who used chlorine gas, generated in situ, to volatilise a Ge matrix as Ge-chloride for the determination of trace impurities by ICP-OES. It was necessary to hold the temperature at $120{ }^{\circ} \mathrm{C}$ to ensure complete volatilisation of the matrix. It should be noted that both of the aforementioned methods have significant health and safety concerns, requiring the use of concentrated sulfuric acid and generation of chlorine gas respectively.

Sun et $a l .{ }^{47}$ reported a headspace, liquid-phase, microsublimation method for the determination of B by ICP-OES. In a simple procedure, $100 \mu \mathrm{L}$ of $\mathrm{NaOH}$ absorption solvent was placed in the bottom of a $0.5 \mathrm{~mL}$ conical tube. $100 \mu \mathrm{L}$ of sample solution was placed in the lid, the tube capped, and inverted on a hotplate at $70{ }^{\circ} \mathrm{C}$. After $10 \mathrm{~h}$ the absorption solvent was analysed for B. They obtained an LOD of $0.008 \mu \mathrm{g} \mathrm{mL} \mathrm{m}^{-1}$ and applied the technique to the determination of $\mathrm{B}$ in plants and waters, with recoveries of between 98.7 and $105.8 \%$. Another novel development was reported by Rastogi et al. ${ }^{48}$ who synthesised $\mathrm{Cu}$-bovine serum albumin (Cu-BSA) nanoparticles and used them for cold vapour generation of $\mathrm{Hg}$. The vapour generation reaction was performed in a $1 \mathrm{~m}$ PTFE reaction coil maintained at $90{ }^{\circ} \mathrm{C}$, and was thought to be due to reduction of $\mathrm{Hg}^{2+}$ by elemental $\mathrm{Cu}^{0}$. LODs of $2.8 \mathrm{pg}$ and $4.1 \mathrm{pg}$ for $\mathrm{iHg}$ and $\mathrm{MeHg}$ respectively were obtained using ICP-MS.

Hydrogen plasma assisted CVG of As, Sb, Se and Te has been proposed by Yang et al. ${ }^{49}$ as a green method because it obviates the need for chemical reagents. In this method, samples were nebulised in the conventional manner in a stream of argon, then passed through the $16 \mathrm{~W}$, hydrogen dielectric barrier discharge (DBD) to generate hydrides, and detected using AFS. The authors speculated that species such as $\mathrm{H}, \mathrm{H}^{+}, \mathrm{H}_{2}{ }^{+}$and $\mathrm{H}_{3}{ }^{+}$ were generated in the plasma and acted as reducing agents. After optimisation for argon and hydrogen flow rates, LODs for $\mathrm{As}, \mathrm{Sb}$, Se and Te were 0.6, 1.4, 1.2 and $1.0 \mathrm{ng}$ respectively.

Photochemical vapour generation $(P V G)$ is an attractive alternative to CVG because it potentially uses fewer reagents, with formic acid usually being the only reductant necessary. Some researchers have added photocatalysts such as $\mathrm{TiO}_{2}$ to improve the efficiency of PVG. Shih et al. ${ }^{50}$ developed a photocatalyst device fabricated from poly(methyl methacrylate) and coated with nano- $\mathrm{TiO}_{2}$. The advantage of this is that is does not require repeated loading of the $\mathrm{TiO}_{2}$ substrate. The device, which was only $150 \times 28 \times 4 \mathrm{~mm}$, was used for PVG of $\mathrm{Se}^{\mathrm{IV}}$ and $\mathrm{Se}^{\mathrm{VI}}$ using formic acid (25 $\mathrm{mM})$ as the reagent and UV irradiation $(40 \mathrm{~W}$ at $365 \mathrm{~nm}$ ). Coupling with ICP-MS yielded LODs of 0.043 and 0.042 $\mu \mathrm{g} \mathrm{L}^{-1}$ respectively. In contrast, Yang et al. ${ }^{51}$ used a slurry of $\mathrm{TiO}_{2}$ nanoparticles onto which were absorbed the $\mathrm{Se}^{\mathrm{IV}}$ and $\mathrm{Se}^{\mathrm{VI}}$ analytes, with subsequent UV irradiation in the presence of formic acid. In this case the LOD was lower at $\sim 0.8 \mathrm{ng} \mathrm{L}^{-1}$ but this was using AFS detection. Clearly, immobilization of $\mathrm{TiO}_{2}$ 
would be the preferred method for future development in order to minimize reagent consumption.

Huang et al. ${ }^{52}$ combined electrokinetic extraction (EKE) and electrochemical vapour generation (EVG) in a single device for the determination of As species by AFS. The integrated cell was fabricated from two PTFE tubes, linked together to form an ' $\mathrm{H}$ ' shape, with one arm containing a graphite working electrode and the other a Pt auxiliary electrode. In operation the whole cell was immersed in $200 \mathrm{~mL}$ of sample to perform the initial EKE, then subsequently removed for EVG, but the exact procedure is not described particularly clearly in the paper. An LOD of $0.020 \mathrm{mg} \mathrm{L}^{-1}$ was obtained for $\mathrm{As}^{\mathrm{V}}$ and recoveries for water samples ranged from 98 to $104 \%$.

\subsection{Solids}

1.3.1 Direct methods. Direct analysis of solid samples using HR-CS-GF MAS has been reported by several groups of workers. Successful determination of $\mathrm{F}$ in plant materials,${ }^{53} \mathrm{Se}$ in soils ${ }^{54}$ and $\mathrm{S}$ in coal and fly $\operatorname{ash}^{55}$ were described. The technique shows potential although all authors conclude that further work is required for a full understanding of the methodology.

1.3.1.1 Glow discharge. Liquid phase diaphragm glow discharge (LDGD) AES is a technique used for the detection of metal ions in aqueous solution. The discharge is formed between two submerged graphite electrodes. Liu and Wang optimised the procedure for the determination of potassium and sodium ions ${ }^{56}$ and lithium ions. ${ }^{57}$ LODs and RSDs were found to be comparable with those of flame AAS.

Micro-hollow cathode GD-OES can be used for analysis of liquid samples as demonstrated by Vander Wal et al. for hydrocarbon determination. ${ }^{58}$ The same authors applied pulsed mode to analyse? solid materials in the form of dry powders. ${ }^{59}$ Both molecular and elemental information were obtained from a range of organic materials and fertilizers. Relative intensities of common spectral signatures were used to distinguish biological agents from common benign organic materials. The micro detection system has potential as a portable hazardous materials sensor.

1.3.1.2 Secondary ion mass spectrometry. The isotopic analysis of micrometer sized uranium bearing particles, released from nuclear facilities, has been proven to be an efficient tool for safeguarding purposes. However these analyses are not always sufficient for identifying specifically some crucial nuclear operations, like uranium conversion, which are most of the time carried out with natural uranium. A SIMS methodology to detect and analyse micrometer sized particles that contain both $\mathrm{U}$ and $\mathrm{F}$ was described. ${ }^{60}$ Following the particle detection, which was performed automatically, individual particles were analysed under microbeam conditions to measure both a precise $\mathrm{U}$ isotopic composition and the relative mass of $\mathrm{F}$. The technique was applied successfully to the analysis of real samples allowing distinction to be made between $\mathrm{U}$ from ores and from a conversion plant.

\subsubsection{Indirect methods}

1.3.2.1 Laser ablation. Laser-induced breakdown spectroscopy (LIBS) and LA-ICP-MS were used simultaneously for spatially resolved mapping of major and trace elements and isotopes within a bastnasite rare earth ore sample, as described by Chirinos et al. ${ }^{61}$ The combination of the two techniques provides complementary measurements for elements that are separately unattainable due to low sensitivity and/or strong interferences. Two dimensional (2D) layer-by-layer mapping, 2D cross-sectional imaging and three-dimensional (3D) volume rendering of elements and isotopes in the bastnasite matrix were presented. These results pave the way for improved 3D elemental imaging through simultaneously acquired LIBS and LA-ICP-MS measurements.

The application of LA-ICP-MS to elemental bioimaging was reviewed by Becker et al. ${ }^{62}$ The capability of the technique to quantify trace elements and isotopes within tissue sections with a spatial resolution ranging about $10-100 \mu \mathrm{m}$ offers major applications in the areas of brain and cancer research, animal model validation, drug development and plant science. Improvements in ablation systems, operation and cell design enabled progressively better spatial resolutions down to $1 \mu \mathrm{m}$. Blaske et al. applied the technique to the analysis of nanosilvercoated bone implants. ${ }^{63}$ This work demonstrated that only the high sensitivity and low detection limits of LA-ICP-MS make this determination possible.

Quantitative analysis of biological tissues can be problematic due to variable sample conditions and changing instrumental parameters during measurement time using LA-ICP-MS. Bonta et al. addressed this problem using gold thin films for internal standardisation. ${ }^{64}$ The gold standardisation was found to compensate for instrumental drifts, matrix related ablation differences and day-to-day signal changes. The RSD of the measurements was around $15 \%$ before standardisation and less than $5 \%$ using gold standardisation and quantitative information was obtained for samples with previously? unknown analyte concentrations. LODs in the range of hundreds of $\mathrm{ng} \mathrm{g}^{-1}$ were achieved. Another approach to internal standardisation and calibration for bioimaging using LA-ICP-MS was proposed by Hoesl $e t a l^{65}$ The procedure was based on printing metal spiked inks onto the top of thin layer samples using an ink-jet printer. The ink was spiked with indium as an internal standard and homogenously printed over the entire membrane prior to LA-ICP-MS detection. An RSD of $2 \%$ was achieved. For the printed calibration standard LODs of $<4$ fmol for different metals and relative process standard deviations of $1-2 \%$ were obtained.

The relatively long measurement time required for chemical imaging of relatively large sample areas using LA-ICP-MS was addressed by Wang et al. ${ }^{66} \mathrm{~A}$ low dispersion sample chamber (tube cell) was developed to improve the imaging capabilities by reducing the single LA shot duration to $30 \mathrm{~ms}$ (full width at $1 \%$ maximum). The tube cell is based on a constant laminar flow and a well-controlled delivery of the laser-ablated aerosol into the transport system, leading to minimised tailing of the aerosol washout and helping to separate the signals even at repetition rates as high as $20-30 \mathrm{~Hz}$. To demonstrate the improved imaging capabilities, microstructured metallic thin film patterns were analysed at a spatial resolution of a few micrometers. The LA-ICP-MS results obtained were comparable 
to synchrotron-based micro-X-ray fluorescence (SR-microXRF). The novel laser LA cell was used to image the distribution of a metal-tagged biomarker in a thin section of breast cancer tissue. Spatial resolution of subcellular (similar to $1 \mu \mathrm{m}$ ) orders was obtained, the level required for morphological assessment in cancer diagnostics.

LA of samples directly into the formed liquid microjunction of a continuous flow surface sampling probe/electrospray ionisation emitter was investigated as a tool for molecular and elemental detection and mass spectrometry imaging. ${ }^{67}$ The ability to efficiently capture and ionise ablated material was demonstrated by the detection of various small soluble $n$-mers of polyaniline and $\mathrm{Ag}$ ion solvent clusters formed from LA of electropolymerised polyaniline and Ag thin films, respectively. In addition, analysis of surfaces that contain soluble components was accomplished by coating or laminating the sample with an insoluble film to enable liquid junction formation without directly extracting material from the surface. The ability to perform mass spectrometry imaging at a spatial resolution of about $50 \mu \mathrm{m}$ was illustrated by using laminated inked patterns on a microscope slide. The data collected demonstrate at least an order of magnitude signal enhancement compared to the noncontact, laser ablation droplet capture-based surface sampling/ionisation approaches previously reported.

A lower cost alternative to conventional laser ablation, using a diode laser, was applied to whole blood analysis by Foltynova et $a .^{68}$ DLTV-ICP-MS is suitable for quantitative elemental analysis of low volume liquid samples and uses low-cost components: a diode laser, a laboratory-built cell and a strip of filter paper. The aerosol generation by DLTV was carried out in a simple cell made up of a glass tube, a near infrared continuouswave diode laser and a common syringe pump. The cell is characterised by minimal dead volume, which reduces turbulent flow and provides very fast wash-out. The paper substrate can hold up to 24 samples; an analysis time per sample of similar to $4.7 \mathrm{~s}$ was achieved. The device performance was optimised, compared to a commercial ablation system and applied to the determination of lead and cadmium in whole human blood without any sample treatment. A prearranged calibration set was printed on the paper strip using a piezoelectric dispenser.

\section{Instrumentation, fundamentals and chemometrics}

\subsection{Instrumentation}

The prospects for microplasma detectors for gas chromatography have been reviewed (81 references) by Meng et al. ${ }^{69}$ Included in the review are CCP, GD and DBD plasma detectors for AES. The advantage of using GC as a sample introduction system is that it is compatible with almost any type of microplasma so, as the authors point out, most advantage is obtained by simplicity, robustness and low cost of operation provided by new technology. With this in mind, the DBD has attracted much interest as a detector for GC and other types of gas and vapour sample introduction. Han et al. ${ }^{70}$ evaluated an atmospheric
DBD for use as a universal GC detector via $\mathrm{C}$ atomic emission at $193 \mathrm{~nm}$. LODs $(0.12-0.28 \mathrm{ng})$ for a variety of VOCs were higher than with FID but the authors state that the detector did not require any reagent gas and could also be used with multiwavelength detection to improve selectivity. Presumably, it could also be used as an element selective detector to rival the CCP, though performance for elements with high IPs might require the use of helium as the discharge gas. Numerous other examples of using the DBD as a miniature detector in atomic spectrometry abound, most of them interfaced with some sort of gaseous sample introduction, which is then hailed as a new miniaturised instrument. Its direct use on liquids is still something of a novelty, however, this mode of operation, a socalled liquid electrode DBD, has been investigated by Krahling et $a .^{71}$ The set-up comprised a polyimide-covered fused-silica capillary (i.d. $700 \mu \mathrm{m}$, o.d. $850 \mu \mathrm{m}$ ) connected to a syringe pump. Downstream, a $400 \mu \mathrm{m}$ diameter tungsten wire provided the other electrode. Acidification of the liquid to $1 \mathrm{~mol} \mathrm{~L}^{-1}$ with $\mathrm{HNO}_{3}$ was required to improve conductivity. The authors determined that analyte transport from the liquid electrode into the plasma was by means of an electrospray-type mechanism, which is distinct from the similar electrolyte as a cathode discharge (ELCAD) source. LODs for 23 metals ranged between 0.016 and $41 \mathrm{mg} \mathrm{L}^{-1}$, which is $2-3$ orders of magnitude higher than the ELCAD, but with a 1-2 order lower flow rate.

A novel variation on the plasma-in-solution concept has been developed by Shirafuji et al. ${ }^{72}$ They constructed a device which had, concentrically, a metal electrode, a dielectric rod-shaped silica pumice $(20 \mathrm{~mm}$ o.d.), and a glass tube. Argon (1.1 L $\min ^{-1}$ ) was passed through the centre of the electrode then emerged from the pumice as small gas bubbles (much like a degassing stone) into deionised water. Application of a squarewave voltage waveform (amplitude $5 \mathrm{kV}$, frequency $20 \mathrm{kHz}$, pulse width $1.2 \mu \mathrm{s}$ ) between the central electrode and a grounding electrode on the outside surface of the glass tube resulted in plasma formation in the bubbles. Time-resolved spectral analysis yielded $T_{\text {rot }}=2000 \mathrm{~K}$ and $T_{\text {vib }}=3000 \mathrm{~K}$ at $t=$ $140 \mathrm{~ns}$, and $T_{\text {rot }}=2000 \mathrm{~K}$ and $T_{\mathrm{vib}}=7000 \mathrm{~K}$ at $t=340 \mathrm{~ns}$. These results reflected the slowness of vibrational compared with rotational relaxation, and the authors note that $T_{\text {vib }}$ is considered to show similar behaviour to $T_{\mathrm{e}}$. Although not used for analytical spectroscopy the device clearly has this potential, with the multiple bubble approach increasing the intensity of emission from the sample medium.

Finally, no discussion of new instrumentation would be complete without mention of a piece of kit designed for being shot into space. Riedo et $a .^{73}$ have evaluated an LA-MS system for planetary exploration in which the laser beam is directed and focussed into a reflectron TOF-MS where the sample is ablated and ionised in situ. The optimised system was evaluated by $\mathrm{Pb}$ isotopic analysis of NIST SRM 98, yielding relative accuracies of e.g. 0.4 per mil for ${ }^{208} \mathrm{~Pb}$ and 7.6 per mil for ${ }^{204} \mathrm{~Pb}$ at concentrations above $100 \mathrm{ppm}$. By the authors own admission, elements/isotopes with low abundances had values in the percent range, though further improvements in detector sensitivity and elimination of noise may improve this. 


\subsection{Fundamentals}

2.2.1 Fundamental constants. During any given review period there are typically several reports of new measurements of fundamental constants. For most practising analytical spectroscopists such data is rarely required, but for those performing diagnostic research reliable fundamental data is like golddust. Most of the fundamental data reported relates to astronomical measurements or plasmas used in nuclear physics so is not really relevant. However, two reports appeared which have some relevance to analytical atomic spectroscopy. Lawler et al. ${ }^{74}$ determined the energy levels and atomic transition probabilities of $299 \mathrm{Sm}(\mathrm{I})$ lines using LIF-FTS. They found good agreement with two of the four previously published datasets but suggested that inadequacies in some of these make their data more reliable. Acharyulu et al. ${ }^{75}$ have measured the hyperfine structure of the ground and excited states of ${ }^{151} \mathrm{Eu}$ and ${ }^{153} \mathrm{Eu}$ isotopes. They determined the isotope shift, between the ${ }^{151} \mathrm{Eu}$ and ${ }^{153} \mathrm{Eu}$ isotopes, for the $4 \mathrm{f}^{7} 6 \mathrm{~s}^{2}\left({ }^{8} \mathrm{~S}_{7 / 2}^{0}\right) \rightarrow 4 \mathrm{f}^{7} 6 \mathrm{~s} 6 \mathrm{p}\left({ }^{8} \mathrm{P}_{9 / 2}\right)$ transition at $601.8154 \mathrm{~nm}$ to be 3549.3(5) MHz. The hyperfine coupling constants for the excited state were reported to be $\mathrm{A}\left({ }^{151} \mathrm{Eu}\right)=664.73(9) \mathrm{MHz}$ and $\mathrm{B}\left({ }^{151} \mathrm{Eu}\right)=290(3) \mathrm{MHz} ; \mathrm{A}\left({ }^{153} \mathrm{Eu}\right)$ $=295.15(7) \mathrm{MHz}$ and $\mathrm{B}\left({ }^{153} \mathrm{Eu}\right)=727$ (2) $\mathrm{MHz}$.

2.2.2 Diagnostics. Diagnostic studies of the fundamental processes in atom and ion cells are useful because they provide information which can be used to improve design, reduce interferences and develop new sources. One of the areas which has attracted considerable research is the temperature measurement of plasmas, which may or may not be in thermal equilibrium. Shelby et al. ${ }^{76}$ used an approach based upon the simultaneous measurement of the thermal emission and the optically saturated fluorescence of a selected atomic transition to check on the existence of LTE. A considerable advantage of this method is that it does not require calibration of the spectrometer nor knowledge of transition probabilities. In practise they formed a plasma using a pulsed Nd:YAG laser (1064 nm) focussed on a glass sample containing $\mathrm{BaO}$. A pulsed, excimerpumped dye laser was then used to populate the excited levels of two $\mathrm{Ba}(\mathrm{II})$ transitions $\left(6 \mathrm{~s}^{2} \mathrm{~S}_{1 / 2} \rightarrow 6 \mathrm{p}^{2} \mathrm{P}_{3 / 2}^{0} ; 455.403 \mathrm{~nm}\right.$ and $6 \mathrm{p}_{2} \mathrm{P}_{1 / 2}^{0}$ $\rightarrow 6 \mathrm{~d}^{2} \mathrm{~S}_{1 / 2} ; 452.493 \mathrm{~nm}$ ) above their thermal values at various delay times from plasma initiation. The measured ratio of the emission and direct line fluorescence signals observed at $614.171 \mathrm{~nm}$ $\left(6 \mathrm{p}^{2} \mathrm{P}_{3 / 2}^{0} \rightarrow 5 \mathrm{~d}^{2} \mathrm{D}_{5 / 2}\right)$ and $489.997 \mathrm{~nm}\left(6 \mathrm{~d}^{2} \mathrm{~S}_{1 / 2} \rightarrow 6 \mathrm{p}^{2} \mathrm{P}_{3 / 2}^{0}\right)$ was related to the excitation temperature of the plasma. Briefly, the main findings were: best results are obtained by working in the UV (large transitions) and for moderate temperatures; the theory is most relevant to optically thin plasmas because self-absorption will affect emission and fluorescence signals differently (particularly outside the laser-excited volume where full saturation does not occur); differences between fluorescence and emission volumes will affect the result; spectral profiles of the laser and absorbing atoms must be considered; and time resolved measurements necessitate the use of a fast detector and electronics. The authors concluded that, while the method is clever and attractive, many experimental obstacles prevent easy application.

Weiss et al. ${ }^{77}$ developed a transition rate model of Mn excitation in argon, neon and argon-hydrogen Grimm GDs. The model took into account the rate of population and depopulation of excited states by summing up transition rates of all observed transitions from and into certain energy levels. The authors reached a number of interesting conclusions regarding the excitation and ionisation processes in the GD, and the formation of metastable states of Mn. Chief amongst these was that the $\mathrm{Mn}$ (II) emission spectrum most likely arose from asymmetric charge transfer with argon and neon ions and possibly Penning ionisation of manganese atoms and $\mathrm{Mn}(\mathrm{I})$ metastables; in the Mn(II) quintet system, transitions from higher lying levels populate some metastable levels; and cascade de-excitation of higher energy levels plays a significant role in the population of lower energy levels from which significant emission occurs. It seems obvious that the excitation and de-excitation rates must be taken into account in order to gain a complete picture of the excited state population, however as the authors point out, considerable experimental work was necessary to accurately identify $\mathrm{Mn}$ (I) and $\mathrm{Mn}$ (II) lines and obtain accurate emission spectra and 'true' line intensities over the spectral range observed.

Yubero et al. $^{78}$ developed a method of measuring $T_{\text {gas }}$ in a microwave discharge using van der Waals broadening of the $\mathrm{Na}$ (I) $588.99 \mathrm{~nm}$ line. The more commonly used $\mathrm{Ar}$ and $\mathrm{H}_{\beta}$ lines are quenched in plasmas containing nitrogen, so this method would be of use for plasmas formed in air or other gases.

Borovinskaya et al. $^{79}$ have continued their interesting and revealing studies of particle behaviour in ICP-MS. They imaged multielement analyte emission from individual droplets passing along the central channel of the ICP using a side-on spectrometer with CCD detector. Droplets were introduced using a microdroplet dispenser and their emission images correlated with transient signals measured using TOFMS. The basic criterion was the temporal shift in the intensity maximum for a particular ion compared with ${ }^{89} \mathrm{Y}^{+}$(which had the earliest occurrence time) obtained by Gaussian fitting of the emission profiles. They found that particles travelling off-axis exhibited greater temporal separation in analyte signal maxima. This was caused by element-dependent fractionation as the vaporised analytes diffused towards the central axis, where the radial velocity gradient continuously separated them in space from the unvaporised droplet residue. Further confirmation of this theory was lent by calculation of the radial velocity profiles of plasma gases and correlation between analyte boiling point and temporal shift, with more volatile analytes being more greatly affected. Another consequence was that the direction of the radial velocity gradient also influenced the order of appearance of the analyte signals for elements of different volatility. This study is a good example of careful observations allied with theoretical calculations, and gives important insights into analyte behaviour in the ICP, particularly for single particle analysis. The same group simultaneously published ${ }^{80}$ a more detailed computational fluid dynamics study of gas flow and rotational motion in the ICP torch, presumably used to inform the aforementioned paper. The model took into account the three concentric argon gas flows through the ICP torch and sampler cone, held at a fixed depth of $10 \mathrm{~mm}$, and power coupling into the plasma. The plasma species $\mathrm{Ar}, \mathrm{Ar}^{+}, \mathrm{Ar}^{2+}$ and 
$\mathrm{e}^{-}$were also included in the model. The main thrust of the research was to optimise conditions of gas flow and power in order to reduce the backward flow of auxiliary gas and to maximise its flow through the region of maximum power coupling. Needless to say, they found that there was an interdependency between the three gas flows, power, and injector tube diameter, and concluded that control of the carrier gas flow rate was the most critical parameter. However, they tempered this with the warning that analyte signal intensity (and presumably interference effects) will also be affected and needs to be taken into account, which is a subject for further investigations. Such models are a useful addition to the diagnostic arsenal for studying the behaviour of the ICP and, allied with empirical observations, yield important insights for the development and optimisation of ion sources for both ICP-MS and ICP-OES.

The $D B D$ has attracted interest as a compact, low-power, microplasma source for MS and AES, following the trend for all things miniature. Shelley et al. ${ }^{81}$ undertook a diagnostic study in an attempt to better characterise it, using TOF-MS to gain an insight into the temporal formation of ions. They generated a pulsed plasma using a He gas flow of $550 \mathrm{~mL} \mathrm{~min}^{-1}$ and a $6 \mathrm{kV}_{\mathrm{p}-\mathrm{p}}$ waveform. Stable operation was achieved at frequencies between 2 and $500 \mathrm{~Hz}$ with sine, triangle, sawtooth, and square waves. The intensity and nature of the various ions varied, unsurprisingly, over the course of the pulse. The authors extrapolated conclusions about ion formation from these temporal profiles, based on the coincidence of reagent and analyte ion peaks, but the results were rather sparse and hence inconclusive. Another study of a helium DBD by Horvatic et al. ${ }^{82}$ focussed on methods to determine $T_{\text {gas }}$ and $n_{\mathrm{e}}$ using the Lorentzian width of $\mathrm{H}_{\alpha}, \mathrm{H}_{\beta}$ and He lines. They found that $T_{\text {gas }}$ was constant across the capillary and was the same as the room temperature $(\sim 320 \mathrm{~K})$, at atmospheric pressure $6.5 \mathrm{kV}$ and 21.5 $\mathrm{kHz}$ operating conditions. They were also able to elucidate broadening parameters of the $\mathrm{H}$ lines caused by neutral He to be: $\gamma_{\mathrm{He}}^{v}(\mathrm{H} \alpha)=1.56 \times 10^{-9} \mathrm{~cm}^{3} \mathrm{~s}^{-1}$ and $\gamma_{\mathrm{He}}^{\nu}\left(\mathrm{H}_{\beta}\right)=3.16 \times 10^{-9}$ $\mathrm{cm}^{3} \mathrm{~s}^{-1}$.

This was a quiet year for furnace fundamentals with only two publications reporting original research. Gupta et al. studied the observed suppression of analyte absorbance in ETAAS in the presence of uranium and thorium matrices. ${ }^{83}$ Arrhenius plots demonstrated that atom formation was similar in aqueous solution and in the studied matrices. SEM studies, however, confirmed that the interaction of the uranium and thorium with the graphite surface resulted in formation of an uneven surface which affects the atomisation efficiency resulting in a reduced absorption signal. Rogulsky et al. $^{\mathbf{8 4}}$ used mathematical modelling to predict the mechanism of palladium modifiers in ETAAS. ${ }^{84}$ The results of the study suggest a desorption mechanism for dissipation of palladium with a direct reaction between palladium and the analyte.

Publications on the use of PMs in ETAAS were reviewed. ${ }^{85}$ The most commonly used PMs: thermally stable carbides, PGMs, and their mixtures were characterised. The sample types considered included organic solutions, suspensions and solid samples, materials after acid decomposition, and natural and drinking water. Results of physicochemical studies of sorbent modifiers were also discussed.

Molecular absorption spectroscopy (MAS), originally developed in the 1970s, is a technique to determine non-metals in flames and graphite furnaces by monitoring the absorbance of diatomic molecules. Early studies employed low resolution instruments designed for line source atomic absorption, which provided a limited choice of analytical wavelengths, insufficient spectral resolution, and spectral interferences. However, the development of HR-CS-AAS instrumentation has allowed the analysis of challenging samples for non-metals as well as some difficult elements to determine by AAS, such as $\mathrm{Al}$ and $\mathrm{P}$. Butcher provided a review covering the theory and the analytical considerations for MAS. ${ }^{86}$ The benefits of HR-CS AAS instrumentation are defined and significant work in the field highlighted.

2.2.3 Interferences. Two types of interferences are commonly encountered, namely spectroscopic and non-spectroscopic. You can be sure that any claim that an analytical technique is 'interference free' will shortly be followed by numerous reports documenting interferences and methods to combat them. Fundamental studies are of great importance to investigating the causes of interferences, because only by understanding how they arise can they be truly eliminated without the need for complex sample pre-treatment methods. Taylor et al. ${ }^{87}$ have published an interesting study of matrix effect in ICP-AES. They started with the widely accepted premise that some matrix effects are caused by radiative cooling of the ICP. In order to investigate this they reversed the process by using a laser to excite ionic resonance lines of the matrix species and observed the effect on emission lines of much lower concentrations of analyte elements. In all cases they observed an enhancement in $\mathrm{Ba}, \mathrm{Mg}, \mathrm{Sr}, \mathrm{Y}$ and $\mathrm{Zn}$ analyte emission in the presences of $\mathrm{Ca}, \mathrm{Mg}$ and $\mathrm{Sr}$ matrices. They attributed this enhancement to heating of electrons in the plasma by superelastic collisions between electrons and excited matrix ions. They calculated that, under normal conditions (i.e. without laser excitation) radiative losses for $0.05 \mathrm{M}$ solutions of a matrix element such as $\mathrm{Ca}$ and Ba were $8.7 \mathrm{~W} \mathrm{~cm} \mathrm{~cm}^{-3}$ and $8.3 \mathrm{~W} \mathrm{~cm}^{-3}$, respectively proposing that this cools the plasma and causes reduced analyte emission. A quite different explanation for signal enhancement in ICP-MS caused by co-existing carbon or bromine was offered by Nakazawa et $a l .^{88}$ They started from the observation that $\mathrm{Br}$ had no effect while carbon caused a signal enhancement, despite having similar ionisation energies of $11.81 \mathrm{eV}$ and $11.26 \mathrm{eV}$ respectively. In order to explain this they suggested that signal enhancements caused by carbon were due to reduction of analyte oxides to free atoms. However, the anomalous signal enhancement of I, which does not readily form oxides, was explained by charge transfer with $\mathrm{CH}$ species, which is an explanation proposed by many previous workers for the enhancing effects of carbon in ICP-MS.

Spectroscopic interferences are typically avoided by choosing alternate lines (in ICP-AES) or isotopes (in ICP-MS). Other methods which have been proposed over the years include interference correction (both ICP-AES and ICP-MS) and the use of doubly charged or oxide ions (ICP-MS). More recently, interferences in 
ICP-MS have been reduced by using some form of reaction cell in tandem with the mass spectrometer. Boting et al. ${ }^{89}$ have developed a novel approach for interference avoidance by using a reaction cell between two quadrupoles to investigate the exothermic asymmetric charge transfer reaction $\mathrm{A}^{+}+\mathrm{O}_{2} \rightarrow \mathrm{O}_{2}^{+}+\mathrm{A}$ between $\mathrm{O}_{2}$ reaction gas and metastable species of the relevant analyte ions. Using this triple quadrupole system to isolate specific analyte $\mathrm{m} / \mathrm{z}$, they observed a linear relationship between the $\mathrm{O}_{2}{ }^{+}$signal and the concentration of $\mathrm{As}, \mathrm{Au}, \mathrm{B}, \mathrm{Be}, \mathrm{Br}, \mathrm{Cl}, \mathrm{I}, \mathrm{P}$ and Se, making this a viable technique for the avoidance of spectral interferences on the ions of these elements. They confirmed that the observed signal at $\mathrm{m} / \mathrm{z}$ of 32 was caused by ${ }^{16} \mathrm{O}_{2}{ }^{+}$by repeating the same experiment using isotopically enriched $(97 \%){ }^{18} \mathrm{O}_{2}$. It should be noted that the authors state that the reaction is only exothermic between $\mathrm{O}_{2}$ and the metastable species of the ions studied (otherwise it is endothermic). This fact should be borne in mind when considering the results of Chiba and Narukawa ${ }^{90}$ who studied the effect of $\mathrm{O}_{2}$ reaction gas on the formation of oxides of As species. They calculated that the reaction $\mathrm{As}^{+}+\mathrm{O}_{2} \rightarrow \mathrm{O}_{2}{ }^{+}+$As is endothermic, but that the $\mathrm{As}^{+}+\mathrm{O}_{2} \rightarrow \mathrm{O}_{2}^{+}+\mathrm{AsO}^{+}+\mathrm{O}$ reaction is exothermic, and favoured to the extent of almost $100 \%$ conversion. Hence, they observed the formation of $\mathrm{AsO}^{+}$as a result of introducing $\mathrm{O}_{2}$ in the reaction cell, rather than the formation of $\mathrm{O}_{2}^{+}$. Presumably the particular experimental set-up and reaction conditions have an influence on the relative rates of these competing reactions, and the different observations of these two groups?

The advent of 'triple quadrupole' ICP-MS has allowed the analyst to exercise much greater selectivity both pre- and postreaction cell, thereby allowing a greater range of reaction chemistries to be utilised. Bolea-Fernandez et al. ${ }^{91}$ have taken advantage of this and used methyl fluoride (10\%) with $\mathrm{He}(90 \%)$ as reaction gas to convert $\mathrm{Al}, \mathrm{Co}, \mathrm{Cr}, \mathrm{Mn}, \mathrm{Ni}, \mathrm{Ti}$, and $\mathrm{V}$ into a variety of product ions with lower interferences. Hence, they were able to perform an interference-free, multi-element determination of these metals in biological fluids with LODs

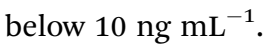

\subsection{Chemometrics}

While there is a large body of research literature on the application of chemometrics to subjects like the origin of foodstuffs, no novel developments of techniques were reported. One paper worth mentioning which, while not chemometrics per se, is in the related area of metrology, is that of Carlson et al. ${ }^{92}$ They suggested a new method for determining the LOQ based on 'the significant figure and relative measurement error ideas due to Coleman, Auses and Gram, coupled with the correct instantiation of Currie's detection limit methodology'. The paper contains a mathematical treatment and derivation resulting in an equation which can be used empirically; only time will tell whether this becomes the de facto standard given that there are numerous methods already in routine use.

\section{Laser-based atomic spectrometry}

This section highlights the most recent key fundamental studies and instrumental developments in laser-based atomic spectrometry, which were published during 2014. In particular, it is dedicated to the main atomic spectrometry techniques where the laser is used as either an intense energy source or a source of precise wavelength, including LIBS, laser atomic absorption spectroscopy (LAAS), CRS and LIF. It should be noted that the use of lasers for fundamental studies of the properties of atoms, and for thin film deposition is not be covered, nor studies related to LA as a sample introduction method.

\subsection{LIBS}

LIBS is one of the most important techniques where the laser is used as an energy source to induce an optical plasma. In 2014, several reviews provided a wide description of this technique, including fundamentals and some novel applications. For instance, Buckley ${ }^{93-95}$ published a three-part-series focusing on major aspects of LIBS, which covered the basics of the LIBS measurement physics and standard applications, the choices and trade-offs for LIBS hardware, and LIBS analysis (e.g. exploring the various ways to go from a LIBS spectrum to the solution of an analytical problem). Additionally, Kurniawan et $a l .{ }^{96}$ reported a comprehensive review of important progress achieved over the last 30 years regarding knowledge of laserinduced plasmas generated by $\mathrm{CO}_{2}$ and Nd:YAG lasers in a variety of ambient gases. In particular, this review showed research results on the use of LIBS for quantitative analysis of light elements, especially hydrogen and deuterium. Spizzichino and Fantoni ${ }^{97}$ reported another review where LIBS was applied either alone or in combination with other spectroscopic techniques (e.g. LIF, Raman) for micro-destructive analysis of materials related to archeometry. Studies on the kinetic energy distributions (KEDs) of ionised species from laser-induced plasmas were reviewed by Wang et al. ${ }^{98}$ In particular, it was discussed how the characteristic features of the ion KEDs, namely the shifted Maxwell-Boltzmann-Coulomb distribution, the rapid temporal evolution, and the anisotropic distribution strongly depend on the employed laser parameters, such as laser power density, pulse duration, and laser wavelength, as well as on the properties of the ambient surroundings and the target material. Moreover, it was reported that the introduction of ambient gas for energetic species mitigation provides a promising method for collisional cooling and charge reduction.

3.1.1 Fundamental studies. During the review period several reports of methods to measure the LIBS plasma parameters, including $n_{e}$ and $T_{e}$, were published. For example, Dzierzega et al. ${ }^{99}$ described the potential of laser Thomson Scattering (TS) to provide a reliable and direct means of determining plasma $n_{\mathrm{e}}$ and $T_{\mathrm{e}}$ with high spatial and temporal resolution. Moreover, it was possible to obtain information about the concentration of heavy particles (useful to investigate the propagating shockwaves outside the plasma) and about their temperature (useful to determine the existence of LTE), making use of the Rayleigh light scattering that inherently accompanies TS. Additionally, Borges et al. ${ }^{\mathbf{1 0 0}}$ developed a fast and precise method for the determination of electron temperature and electron number density based on the use of a simple artificial 
neural network (ANN). It was demonstrated that the AAN method provides great potential for real-time diagnostics of the plasma parameters, which could be useful both for fundamental studies and industrial applications.

The overall detection efficiency of any LIBS system is a function of wavelength; therefore, the instrument must be carefully calibrated over a wide wavelength range. Quartz tungsten halogen lamps are widely used as spectral irradiance and radiance standards due to their continuous smooth emission from 250 to $2400 \mathrm{~nm}$. However, these devices call for expensive recalibration after a certain number of working hours. As an alternative and easy-to-implement way of calibrating the response, Li et al. ${ }^{\mathbf{1 0 1}}$ reported the use of the wellknown Ar branching ratio. They showed that this method, in a laser-induced argon plasma, provided results fitting well (e.g. similar calibration uncertainty) with those obtained using a standard quartz tungsten halogen lamp and the argon branching ratio method in an argon-filled hollow cathode lamp.

3.1.2 Instrumentation. I. B. Gornushkin et al. ${ }^{\mathbf{1 0 2}}$ investigated the proof-of-principle of a LIBS system combined with a spatial heterodyne spectrometer (SHS), which consisted of a modified version of the Michelson interferometer in which mirrors were replaced by diffraction gratings. The output signal of the SHS was an interferogram which was Fourier-transformed to retrieve the original plasma spectrum. The SHS provided about 200 times higher throughput than that of a typical dispersive spectrometers used in LIBS. Additionally, it was claimed that LIBS-SHS could be developed into a portable, inexpensive, rugged instrument for field applications.

3.1.3 Novel LIBS approaches. Several approaches were investigated to improve the sensitivity provided by LIBS. For instance, the fundamental aspects of emission enhancement taking place in nanoparticle enhanced LIBS (NELIBS) were discussed by De Giacomo et al. ${ }^{\mathbf{1 0 3}}$ The enhancement of the emission spectra (e.g. 1-2 orders of magnitude) was found to be mainly ascribed to the presence of multiple ignition points and the instantaneous escape of electrons due to field emission processes that occur when metallic NPs are deposited on the surface of conductors. Moreover, differential ablation of NPs that occurs when they are deposited on non-conducting samples (e.g. due to extremely low thermal conductivity of NPs themselves), was used for the characterisation of NPs in terms of concentration and size. The main advantages of NELIBS were summarised to include: simplicity of the NP deposition operation, immediate applicability to commercial instrumentation, large enhancement of the emission spectra of conductors, high reproducibility, single shot measurement, and possibility of determining NP concentration and size.

Antenna-coupled microwave-assisted LIBS was studied by Tampo et al. ${ }^{\mathbf{1 0 4}}$ to enhance the emission intensity in an attempt to solve the issue of sensitivity reduction in super-high resolution spectrometers, which are required for nuclear fuel analysis. The pulsed microwave input temporally sustained plasma emissions of excited Gd ions for a period of around $300 \mathrm{~ms}(10$ times longer than without microwave coupling). By integrating the temporal emission of excited Gd ions, a 50-fold increase in emission intensity was achieved. Likewise, Liu et al. ${ }^{\mathbf{1 0 5}}$ investigated flame-enhanced LIBS to improve the sensitivity and spectral resolution by generating a laser-induced plasma in the blue outer envelope of a neutral oxy-acetylene flame. In particular, a high-temperature and low-density plasma was generated, providing enhanced emission line intensity and narrowed lines in the LIBS analysis of low alloy steel targets.

Novel LIBS methods were also investigated to improve the determination of halogen elements, which provide some difficulties due to their high ionisation potential. For example, Álvarez et $a l .{ }^{\mathbf{1 0 6}}$ investigated the development of a LIBS method to determine the fluorite $\left(\mathrm{CaF}_{2}\right)$ mass-content of powdered ore samples. This method was based on the LIBS detection of different CaF molecular bands in ambient air conditions, and it was shown as an alternative to the use of atomic fluorine emission lines (e.g. F(I) at $685.60 \mathrm{~nm}$ ) in a helium atmosphere. Zhang et al. ${ }^{107}$ investigated iodine detection of $\mathrm{CH}_{3} \mathrm{I}$ in buffer gases of $\mathrm{N}_{2}$, using low pressure LIBS under different experimental conditions. In particular, it was demonstrated that it was possible to achieve a low detection limit (about $60 \mathrm{ppb}$ ) for iodine in $\mathrm{N}_{2}$, using low pressure (700 Pa) ns-LIBS and integrating the iodine emission signal at $183 \mathrm{~nm}$.

The capabilities of LIBS for $2 D$ and $3 D$ analysis were investigated by several authors. In particular, Beresko et al. ${ }^{\mathbf{1 0 8}}$ demonstrated the possibility of performing 3D multielemental chemical maps of complex-shaped surfaces without any additional equipment for the determination of the best focal position. Direct monitoring of the LIBS signal intensity was used to correct the focusing lens-to-sample distance. This method allowed the scanning of surfaces with large height fluctuations (i.e. $\mathrm{mm}$ ) without the need of any additional devices, and improved the measurement reproducibility. LIBS might be also applied for depth profiling of thin coatings due to the possibility of achieving very shallow ablation depth per pulse $(e . g$. a few nm per pulse). Nevertheless, the depth resolution might be much higher than the ablation depth per pulse due to non-uniform emitted spectra over several laser shots. In this context, Banerjee and Fedosejevs ${ }^{\mathbf{1 0 9}}$ investigated whether the observed spectrum obtained for single laser shot ablation reflects the average composition of all the material ablated, or whether materials close to the top surface contribute more to the emission. Their results showed that plasma formed at the surface layer exhibited a strong LIBS signature while the deeper melted layer contributed very little to the single shot LIBS signal. Therefore, the emission spectra did not necessarily reflect the actual average depth profile composition in single shot LIBS.

The LIBS technique is known to be able to provide quantitative analysis. Nevertheless, strong matrix effects can degrade the precision and accuracy. In this context, Glaus and Hahn ${ }^{\mathbf{1 1 0}}$ reported the application of double-pulse laser ablation (DP-LA) to improve the analyte response and the achievable precisions of LA-LIBS, which is an analytical method that minimises sample matrix effects. Two coaxial laser beams were directed at the ablation site and the analytical signals were then collected from a LIBS plasma downstream of the ablation site. This enhanced ablation yield and produced, to some extent, a finer aerosol structure which was more efficiently vaporised and dissociated in the analytical LIBS plasma. A linear response was observed 
for $\mathrm{Mn}$ across the different matrices (except for Al samples), allowing for non-matrix-matched calibrations. Furthermore, D'Andrea et al. ${ }^{\mathbf{1 1 1}}$ developed an approach based on ANN for LIBS quantitative analysis. A preliminary step of dimension reduction was used to achieve the desired accuracy while minimising the complexity of the approximating neural model. In particular, the number of input variables (e.g. intensities of spectral lines) was reduced to the minimum using forward feature selection. Acceptable values of trueness accuracy and precision for the analysis of bronze alloys were achieved in a way that the analysis could be easily automated. It was considered that this quantification method has great potential for the continuous monitoring of the composition of large numbers of metal samples in industrial applications.

An improved method to measure the isotopic ratio of boron samples with high precision was investigated by Sarkar et al. ${ }^{112}$ using laser ablation molecular isotopic spectrometry (LAMIS). Different spectral normalization and pre-treatment procedures were applied to the raw spectra and analyzed by PLSR. First order differentiation of the spectra followed by normalizing with respect to the highest value was found to give optimum precision. A precision of $9 \%(2 \sigma)$ on the boron isotopic ratio was achieved using 1000 single shot LAMIS spectral accumulation.

In relation to LIBS analysis under water, Hou et al. ${ }^{113}$ investigated the analysis of natural seawater at different pressures (from 0.1 to $40 \mathrm{MPa}$ ) in order to demonstrate the potential of this technique for in situ analysis at $4000 \mathrm{~m}$ depth in the ocean. Plasma emission was found to be slightly dependent on the ambient pressure during the early stage of plasma but the external pressure significantly affected plasma emission during the late stage. In the same context, SP-LIBS and DP-LIBS with a collinear laser beam orientation were investigated by LawrenceSnyder et al. ${ }^{\mathbf{1 1 4}}$ for high-pressure bulk aqueous solutions (up to 50 bar). In SP-LIBS the plasma forms in a static liquid environment while the DP-LIBS plasma forms in a dynamic bubble environment which is significantly influenced by solution pressure. The results showed that DP -LIBS emission intensity was directly proportional to the size of the laser-induced bubble, at all evaluated pressures. Nevertheless, high solution pressures confined the expanding bubble to a greater extent, causing the bubble to collapse earlier (decreasing the bubble lifetime), which in turn prevented the bubble from reaching the maximum volume observed at lower pressures.

\subsection{Laser atomic absorption spectroscopy (LAAS)}

Infrared LAAS is a promising modern technique for sensing trace gases with high sensitivity, selectivity, and high time resolution. Zhang et al. ${ }^{115}$ reviewed some important developments in modern laser absorption spectroscopy based on the use of quantum cascade laser (QCL) sources, which provide narrow linewidths, single mode operation, tunability, high output power, reliability, low power consumption, and compactness. In particular, their review focused on selected absorption spectroscopy applications of QCLs for molecular spectroscopy, industrial process control, combustion diagnostics, and breath analysis in clinical studies.

\subsection{Cavity ringdown spectroscopy (CRDS)}

Continuous wave-CRDS requires a rapid termination of the injection of light into the cavity to initiate the decay event. Therefore, Bostrom et al. ${ }^{116}$ developed a novel technique to move the ringdown laser off resonance in less than a microsecond, while not interfering with cavity locking, by injecting a second pulsed diode laser into the main laser. The second laser that modulates the main laser's refractive index provided a frequency shift (up to $100 \mathrm{MHz}$ ) sufficient to unlock laser-cavity optical feedback, demonstrating its utility in CRDS. Data on the frequency shift as a function of both main laser current and relative wavelength were presented, as well as a demonstration that single exponential decays were maintained in the process.

An extremely sensitive and simple fiber loop-cavity ringdown spectroscopy setup was designed by Berberoglu and Altan, ${ }^{117}$ using a pulsed nanosecond laser source working near $1535 \mathrm{~nm}$ (e.g. C-band window). The system sensitivity was found to be of the order of $0.01 \mathrm{~dB}$ after extracting the characteristic macrobend loss curve of a standard single mode fiber (SMF-28). It was claimed that this simplified CRDS system might have a great potential in versatile applications (e.g. detection of some trace gases like ammonia) where quick results are necessary without the system complexity.

\subsection{Laser-induced fluorescence (LIF)}

It is well known that fs-laser pulses are well suited for twophoton laser-induced-fluorescence (TPLIF) imaging of key atomic species such as $\mathrm{H}, \mathrm{N}$, and $\mathrm{O}$ in gas-phase reacting flows. Kulatilaka et al. ${ }^{\mathbf{1 1 8}}$ developed a home-built fs-FHG system that had an overall per-pulse conversion efficiency of nearly $2 \%$ around $200 \mathrm{~nm}$ at high repetition rate $(10 \mathrm{kHz})$, for two dimensional, fs-TPLIF imaging of $\mathrm{H}$ atoms in flames. This overall conversion efficiency was more than six times greater than that of commercial OPA-based systems.

\section{Isotope analysis}

This section examines progress in the measurement of isotope ratios, using a variety of mass spectrometric methods. Plasma source ionisation is notably the driver of the ever-widening field of natural stable isotope variations of metallic elements. However, some practical issues with the concentration of the element of interest, isobaric interferences and solution blanks mean that accelerator mass spectrometry (AMS) and thermal ionisation mass spectrometry (TIMS) are favoured techniques for some isotope systems. Double spiking is an expanding method to neutralise instrumental and procedural massdependent fractionation in both stable and radiogenic isotope systems. Many studies have combined both double spike and standard-sample bracketing methodologies and made comparisons between the precision achieved by both methods. An overlap is emerging between the measurement of uranium isotope variation in natural systems and the $U$ isotope determination for the nuclear forensic or monitoring/safeguarding fields. Coincident analytical techniques between these fields is 
likely to produce useful advances in the analysis of nuclear materials.

\subsection{Instrumental developments}

Uncertainty or drift in isotopic data can be generated where transient signals are produced by sample introduction systems such as laser ablation or ion chromatography. The cause of this isotopic drift, and a potential solution, was investigated by Gourgiotis et al. ${ }^{119}$ Their study confirmed that a component in the isotope ratio scatter was caused by time lag differences between amplifier responses. A remediation was then developed in which raw isotope signals for each mass were effectively synchronised. This resulted in a factor of 20 improvement in the measurement uncertainty of $\mathrm{Pb}$ isotope ratios when using FI and a DIHEN in conjunction with a MC-ICP-MS.

Resistors of different magnitudes are becoming a must-have accessory for Faraday cup amplifiers on multi-collector mass spectrometers. Standard-issue $10^{11} \Omega$ resistors are capable of translating ion beams between $5 \times 10^{13} \mathrm{~A}$ and $4.5 \times 10^{10} \mathrm{~A}$. However, for simultaneous measurement of large and small magnitude isotopes a lower order resistor (e.g. $10^{10} \Omega$ ) for the larger beam may be appropriate, especially where sample size is unrestricted. Higher precision on large magnitude ratios, for example ${ }^{238} \mathrm{U}:{ }^{234}$ or ${ }^{235} \mathrm{U}$ with limited analyte, can potentially be achieved using a higher impedance resistor (e.g. $10^{12} \Omega$ ). Development and testing of newly manufactured $10^{13} \Omega$ resistors were documented by Koornneef et al. ${ }^{\mathbf{1 2 0}}$ which in theory have 10 times lower noise levels than the $10^{11} \Omega$ variant. Trials using Sr and Nd loads of $10 \mathrm{pg}$ via TIMS indicated that ${ }^{87} \mathrm{Sr}:{ }^{86} \mathrm{Sr}$ and ${ }^{143} \mathrm{Nd}:{ }^{144} \mathrm{Nd}$ could be resolved to the fourth decimal place of their ratios (i.e. $\pm 3.3 \%$ o). A cautionary note raised by these authors is that at such sample concentrations, the level of procedural blank becomes of paramount importance to the accuracy of the measured isotope ratio.

Ireland et al. ${ }^{121}$ introduced a new all-Teflon HPLC system. This was developed in response to the need for an automated chromatographic system that combined fine-scale gradients in acid strength and permitted highly concentrated acids. Potential applications in the geoscience field include $\mathrm{Ni}-\mathrm{Mg}$ separation for $\mathrm{Ni}^{60}{ }^{6 e} \mathrm{Fe}$ studies and separation of individual multiisotopic REEs.

\subsection{Radionuclide isotope ratio analysis}

A review paper by Kutschera ${ }^{122}$ succinctly summarised the "Applications of accelerator mass spectrometry" in terms of radionuclide measurement. The work provided an informative overview of the research areas where AMS measurements are used, with applications being summarised according to their use in the atmosphere, biosphere, hydrosphere, cryosphere, lithosphere, cosmosphere or technosphere. Conveniently, a companion review in the same issue by Synal $^{123}$ covered the technical developments in AMS. This is focussed on how the instrumentation has evolved and how developments in the ionisation, detection and instrument layout have benefited radionuclide analysis.
Yin et $a .^{\mathbf{1 2 4}}$ experimented with AMS measurement of uranium in $5 \mathrm{ng}$ samples. They reported a consistent agreement of measured ${ }^{234,235,236} \mathrm{U}:{ }^{238} \mathrm{U}$ relative to certified ratios for internal standards, with ratios spanning four orders of magnitude. AMS is commonly used for $\mathrm{U}$ and $\mathrm{Pu}$ analysis, but Christl et $a .^{\mathbf{1 2 5}}$ examined the potential for extending analysis to the higher actinides: $\mathrm{Am}$ and $\mathrm{Cm}$. Their results indicated that detection limits for ${ }^{241} \mathrm{Am}$ and the $\mathrm{Cm}$ isotopes were in the range $1 \mathrm{fg}$ to $100 \mathrm{ag}$ respectively, potentially opening the AMS technique to bioassay applications. A ${ }^{237} \mathrm{~Np}$ measurement protocol by AMS was outlined by Wang et al. ${ }^{126}$ with sensitivity reported as $<10^{-11}$ on ${ }^{237} \mathrm{~Np}:{ }^{238} \mathrm{U}$.

Post Fukushima, ${ }^{134} \mathrm{Cs}:{ }^{137} \mathrm{Cs}$ has been used as a tracer of environmental contamination. However, the short half-life of ${ }^{134} \mathrm{Cs}$ encouraged Zheng et $a .^{127}$ to examine the use of ${ }^{135} \mathrm{Cs}:{ }^{137} \mathrm{Cs}$ as an alternative for longer-term monitoring. A protocol that involved ammonium molybdophosphate Cs adsorption, chromatographic separation and ICP-MS/MS was used for ${ }^{135} \mathrm{Cs}$ and ${ }^{137} \mathrm{Cs}$ measurement. The reported detection limits, $0.01 \mathrm{pg} \mathrm{mL} \mathrm{m}^{-1}$ and $0.006 \mathrm{pg} \mathrm{mL}^{-1}$ respectively, are the lowest for any ICP-MS study to date.

Detection of anthropogenic nuclear isotopes at picogram levels is often an expensive and prolonged procedure. Ezerinskis et al. ${ }^{128}$ described a method to evaluate the abundance of ${ }^{129}$ I using ion chromatography combined with ICP-SFMS. Their procedure proved reliable for quantification of ${ }^{129} \mathrm{I}$ with a detection limit of $0.7 \mathrm{pg} \mathrm{g}^{-1}$. Uranium isotope measurement of micrometre-scale particles was the subject of a study by Hubert et al. ${ }^{129} \mathrm{~A}$ femtosecond laser-ICP-MS combination optimised for laser shot repetition rate produced reproducibility of ${ }^{238} \mathrm{U}:{ }^{235} \mathrm{U}$ better than $4 \%$ from $<200 \mathrm{pg}$ U. Individual $1 \mu \mathrm{m}$ plutonium particles have been analysed via HR-ICP-MS by Miyamoto et $a l .{ }^{130}$ with the objective of measuring the time since last $\mathrm{Pu}$ purification. HR-ICP-MS and a ${ }^{243} \mathrm{Am}$ spike were used to determine the age, which could be constrained between uncertainties of 2 and 6 months. This is thought to provide suitable constraints on environmental samples in nuclear safeguard inspections.

Uranium isotope ratio measurement by TIMS was revived by Quemet et al., ${ }^{\mathbf{1 3 1}}$ who used a total evaporation method. Their results indicated that reproducibility for ${ }^{234} \mathrm{U}:{ }^{238} \mathrm{U}$ and ${ }^{235} \mathrm{U}:{ }^{238} \mathrm{U}$ was better than $0.5 \%$ and $0.1 \%$ respectively, on sample sizes of $50 \mathrm{ng}$.

Recent investigation into the natural variations of uranium isotope ratios was continued by Uvarova et $a l .{ }^{132}$ Their study examined the $\delta^{234} \mathrm{U}$ and $\delta^{238} \mathrm{U}$ systematics of uranium ore deposits using ${ }^{233-236} \mathrm{U}$ double spike and MC-ICP-MS. $\delta^{234} \mathrm{U}$ ratios should be in secular equilibrium $\left(\delta^{234} \mathrm{U} \sim 0 \%\right.$ and deviations from this were attributed to recent $(<2.5 \mathrm{Ma})$ leaching or addition of ${ }^{234} \mathrm{U}$. Isotope fractionation of ${ }^{238} \mathrm{U}:{ }^{235} \mathrm{U}$ was identified amongst the ores from different types of deposits, and was found to vary in response to the redox state of the depositional environment and the isotopic signature of the metallogenic source material. An application of these was suggested as the use of $\delta^{238} \mathrm{U}$ as an indicator of ore-grade with a trend to lighter ratios in proximity to the redox centre. Murphy et $a .^{\mathbf{1 3 3}}$ examined natural uranium isotope variation in 
groundwaters and mineralised sediments in the proximity of a sandstone-hosted uranium ore deposit. ${ }^{238} \mathrm{U}:{ }^{235} \mathrm{U}$ variation between $2 \%$ and $5 \%$ in the water was attributed to a unidirectional kinetic isotope fractionation. A progressive shift to lighter isotope compositions in the water was associated with precipitation of uranium-bearing minerals.

\subsection{Radiogenic isotope measurement}

Systems with four or more stable isotopes are open to a three dimensional analysis of their isotope ratios. Regression of data within such systems has been investigated by McLean, ${ }^{134}$ who used TIMS to measure an equal atom Pb standard, NIST SRM 982, to produce a multi-isotope fractionation trajectory. These trajectories correlated well with linear and Rayleigh massdependent fractionation trends (in log-ratio coordinates) for even mass $\mathrm{Pb}$ isotopes, but with a modified exponential law for ${ }^{207} \mathrm{~Pb}$ - a mass-independent fractionation characteristic also noted by Thirlwall (M. F. Thirlwall, Ch. Geo., 2000, 163(1-4), 299-322) also for TIMS analyses.

Taylor et al. ${ }^{135}$ provided a re-assessment of the precision of lead isotope measurement by multi-collector mass spectrometry, and examined methods for further enhancement in the future. Four methods of mass fractionation correction were assessed: constant $f$, Tl-spiking, double/triple-spiking and sample-standard bracketing. Of these, the poly spiking methodologies clearly provided the highest quality data $( \pm 0.01 \%$ on ${ }^{206} \mathrm{~Pb}:{ }^{204} \mathrm{~Pb}$ ). Beyond this, the paper examined the prospects for enhancing the measurement precision of $\mathrm{Pb}$ isotopes in Earth sciences via multiple analysis and high impedance resistors in the detection system. This potential was demonstrated using the isotopic averages of several rock units from a single volcano. Average values from all units were found to lie on a remarkably tight trend, not apparent from individual analyses. An outcome could be well constrained mixing lines with tightly defined end member isotope compositions. Dronov and Schram ${ }^{136}$ provided a method for improved $\mathrm{Pb}$ and $\mathrm{Sr}$ isotope measurement using quadrupole ICP-MS. By measuring a stepped concentration series of an element, isotope ratios were formulated as the gradient of the line between the two varying isotope signals. Results were presented as per mil deviation from a reference material, and indicated that reproducibility was $\pm 0.07 \%$ for ${ }^{207} \mathrm{~Pb}:{ }^{206} \mathrm{~Pb}$ ratios.

In situ measurement of isotope ratios on planetary surfaces requires a suitably miniaturised analytical system, capable of useful precision. Riedo et $a .^{73}$ described the results for $\mathrm{Pb}$ isotope measurement via laser ionisation followed by a reflector-type time-of-flight mass analyser. Measurement precision of $0.02 \%$ for ${ }^{207} \mathrm{~Pb}:{ }^{206} \mathrm{~Pb}$ was determined for NIST SRM 981 and galena analysis, which compares favourably with nondouble spike TIMS analysis.

Dating of mineral phases using $\mathrm{U}-\mathrm{Pb}$ systematics is a continuously improving field, exemplified by Chew et al. ${ }^{137}$ These authors have evaluated accessory mineral U-Pb geochronology by LA-ICP-MS using apatite and titanite of known ages. The novel aspect of their method was the approach to common $\mathrm{Pb}$ correction using the Iolite data reduction software. This allowed for variable amounts of common $\mathrm{Pb}$ in the accessory phase, and produced uncertainties $\pm 1 \%$ for apatite ages between 30 and $500 \mathrm{Ma}$.

Determination of ${ }^{143} \mathrm{Nd}:{ }^{144} \mathrm{Nd}$ in the same analysis as Sm:Nd can be completed by IDA if a correction is made for isotopic overlaps from the added spike. However, Cheong et al. ${ }^{138}$ have assessed the potential for combined ${ }^{143} \mathrm{Nd}:{ }^{144} \mathrm{Nd}-\mathrm{Sm}: \mathrm{Nd}$ measurement to be made by MC-ICP-MS without recourse to spiking: Sm:Nd being calibrated externally by standard sample bracketing. Results for RMs agreed well with recommended values provided a matrix-matched external standard was used in place of an aqueous standard solution.

Producing higher precision isotope ratios with diminishing elemental concentrations is a motive for achieving increased sensitivity. As such, Crocket et al. ${ }^{139}$ have re-invigorated the measurement of $\mathrm{Nd}$ isotopes in oxide form via TIMS with the aim of improving the isotopic characterisation of fossil corals. Using Eichrom RE-spec and Ln-spec separations followed by focussed filament loading, ion beams of $6 \times 10^{12} \mathrm{~A} \mathrm{ng}^{-1}$ were achieved. Interferences from other rare earth oxides were removed using ${ }^{16} \mathrm{O}::^{17} \mathrm{O}:{ }^{18} \mathrm{O}$ systematics for their laboratory. External reproducibility of coral ${ }^{143} \mathrm{Nd}:{ }^{144} \mathrm{Nd}$ was determined as $\pm 16 \mathrm{ppm}(2 \mathrm{~s})$ with between 10 and $30 \mathrm{ng}$ sample loads.

Konter and Storm ${ }^{140}$ tackled the sticky problem of ${ }^{87} \mathrm{Sr}:{ }^{86} \mathrm{Sr}$ measurement by MC-ICP-MS. TIMS remains the method of choice to measure this radiogenic isotope ratio due to ${ }^{84} \mathrm{Kr}$ and ${ }^{86} \mathrm{Kr}$ isobaric interferences in plasma-based systems. The authors developed a within-run deconvolution of ${ }^{84} \mathrm{Kr}$ from ${ }^{84} \mathrm{Sr}$ in order to estimate ${ }^{86} \mathrm{Kr}$ on ${ }^{86} \mathrm{Sr}$ and then an exponential $\mathrm{Sr}$ mass fractionation correction. Long-term precision of NIST SRM $987{ }^{87} \mathrm{Sr}:{ }^{86} \mathrm{Sr}$ was $\pm 16 \times 10^{-6}$, which compares favourably with typical TIMS reproducibility.

Faraday cups equipped with amplifiers other than the "standard issue" $10^{11} \Omega$ variant are expanding the possibilities of measuring samples with low concentrations of the element of interest or with large magnitude isotope ratios. Liu and Pearson ${ }^{141}$ provided an assessment of the use of $10^{12} \Omega$ amplifiers in measuring Os isotope ratios as oxides on N-TIMS. A useful function of this study is a clear evaluation of the amount of Os required to generate a particular ion beam size and, in turn, the expected reproducibility error under these conditions. Errors of better than $50 \mathrm{ppm}$ on the ${ }^{187} \mathrm{Os}:{ }^{188} \mathrm{Os}$ and ${ }^{186} \mathrm{Os}:{ }^{188} \mathrm{Os}$ were generated from $1-3 \mathrm{ng}$ loads, with little degradation in data quality down to $0.1 \mathrm{ng}$ Os.

\subsection{Stable isotope systematics}

Natural variation in "non-traditional" stable isotopes (e.g. $\mathrm{Cu}$, $\mathrm{Fe}, \mathrm{Mg}$, Mo etc.) is an expanding field. This section documents the developments in stable isotope measurement in order of increasing mass. Uranium stable isotope studies are covered in radionuclide isotope ratio analysis: Section 4.2 above.

Like more traditional stable isotope elements ( $\mathrm{O}, \mathrm{S}, \mathrm{C}$ etc.), understanding the processes that drive mass dependent and mass independent fractionation requires an appreciation of chemical physics. This was the subject of a timely review by Eiler 
et $a{ }^{142}$ who assessed our current knowledge base in this field using examples taken from the O, Sand C isotope systems.

An interlaboratory comparison of boron isotope measurement was the focus of a study by Foster et al. ${ }^{143}$ Data from a coherent set of samples was reported from two negative ion TIMS and two MC-ICP-MS instruments in different laboratories. Low-matrix samples, i.e. effectively pure boron, produced comparable $\delta^{11} \mathrm{~B}$ between the laboratories, with differences falling within the range of measurement uncertainty for the laboratories. However, $\mathrm{CaCO}^{3-}$ rich samples gave a spread of $\delta^{11} \mathrm{~B}$ which was larger than the expressed uncertainty. Despite this, the high-matrix samples measured in individual laboratories were found to have consistent $\delta^{11} \mathrm{~B}$ offset. This indicated that determinations made within each laboratory would preserve the relative $\delta^{11} \mathrm{~B}$ differences between samples.

A direct injection nebulisation system linked to MC-ICP-MS was used by Louvat et al. ${ }^{\mathbf{1 4 4}}$ to assess boron isotope analysis. A key advantage of this method was the high sample throughput, short wash-out time and continuous peristaltic pump operation, meaning tighter sample-standard bracketing and greater instrument stability between analyses. Repeatability for boric acid solutions was $< \pm 0.1 \%$ at $2 \mathrm{~s}$, but was found to be $\pm 0.2 \%$ o for natural samples processed through chemical separation.

Separation of boron from silicate samples using a microsublimation technique was investigated by Pi et al. ${ }^{\mathbf{1 4 5}}$ Concentrated $\mathrm{NaCl}$ solution was added to dissolved silicate rocks, which significantly reduced the Si content of the vapour phase while preserving a high B recovery. Excluding a chromatographic separation of $\mathrm{B}$ also reduces the acid-derived procedural blank.

Berman et al. ${ }^{146}$ provided a perspective on oxygen isotope analysis by Off-Axis Integrated Cavity Output Spectroscopy (OAICOS). For water standards this technique was demonstrated to have a similar precision to conventional mass spectrometric analysis. However, it has a major advantage in completing isotope measurement on liquid water without conversion. Rapid, multiple analysis of $\delta^{17} \mathrm{O}$ and $\delta^{18} \mathrm{O}$ enabled reproducible values for ${ }^{17} \mathrm{O}$-excess (where ${ }^{17} \mathrm{O}$-excess $=\ln \left\{\delta^{17} \mathrm{O}+1\right\}-0.528 \ln$ $\left\{\delta^{18} \mathrm{O}+1\right\}$ ), potentially expanding the use of this parameter in studies of the water cycle, atmospheric convection, and climate modelling. Initial measurements of $\mathrm{D}: \mathrm{H}, \delta^{17} \mathrm{O}$ and $\delta^{18} \mathrm{O}$ in water were reported by Wu et al. ${ }^{147}$ using a compact isotope ratio laser spectrometer. These workers predicted further improvements in the precision of this instrumentation with refinement to the sample introduction system and control of temperature drift in the gas cell.

A timely review of $\mathrm{Mg}$ isotope analysis via MC-ICP-MS by An and Huang ${ }^{148}$ examined the properties of the four main commercial instruments, assessed the chemical isolation techniques, and summarised the key isobaric interferences that can plague $\mathrm{Mg}$ isotope determinations. Of most interest is the tabulated and graphical compilation of $\mathrm{Mg}$ isotope data for RMs and rock standards in which the compiled data is traceable to a specific publication and measurement laboratory. This review is particularly pertinent as it provides a partial answer to the request of Brand et al. ${ }^{\mathbf{1 4 9}}$ for new anchor values for stable isotope delta parameters for secondary isotopic RMs, particularly for the heavier (>20 amu) elements. Issues with $\mathrm{Mg}$ isotope measurement were investigated by Teng and Yang ${ }^{\mathbf{1 5 0}}$ who used two MC-ICP-MS instruments in their study. Influence of matrixmatching between samples and standards, host acid molarity and $\mathrm{Mg}$ concentration were all found to have an influence on $\delta^{26} \mathrm{Mg}$; effects that were found to be considerably different between the two instruments. Wet plasma sample introduction was found to have a reduced matrix effect compared to a dry plasma system.

Using MC-ICP-MS to determine sulfur isotope ratios is hampered by an array of isobaric interferences from double charged and polyatomic species. Lin et al. ${ }^{151}$ overcame these issues using a medium mass resolution $(m / \Delta m \sim 3000)$ and matrix matched standards. This approach enabled highly reproducible $\delta^{34} \mathrm{~S}$ to be measured on water samples (including seawater) without chemical purification.

Lehn et al. ${ }^{152}$ reported a best practice method for measuring $\delta^{44 / 40} \mathrm{Ca}$ by TIMS using a ${ }^{43} \mathrm{Ca}-{ }^{42} \mathrm{Ca}$ double spike. Optimisation modelling of double spike mixing proportions and measurement parameters was tested on standards. Results indicated an external reproducibility of $\pm 0.04 \%$ o $(2 \sigma \mathrm{SD})$, which is a two to tenfold improvement on previous double spike TIMS methods.

High-resolution titanium isotope systematics were the subject of a study by Millet and Dauphas ${ }^{\mathbf{1 5 3}}$ using MC-ICP-MS in conjunction with a ${ }^{49-47} \mathrm{Ti}$ double spike. An interesting facet of their double spike analysis is the recognition of $\mathrm{Ti}$ isotope fractionation during chemical purification via the difference noted with bracketed standard-sample $\beta$ factors. However, the addition of double spike prior to sample preparation reliably accounted for this effect. Precision of the method is reported as $0.02 \%$ for $\delta^{49} \mathrm{Ti}$, with data quoted relative to a new isotope reference standard: OL-Ti.

Interference from oxides and nitrides is a particular issue with the accurate determination of ${ }^{53} \mathrm{Cr}$ and ${ }^{54} \mathrm{Cr}$ systematics. Schiller et al. ${ }^{154}$ reported a four-step column chromatographic procedure of $\mathrm{Cr}$ isolation prior to measurement. Isobaric interferences from ${ }^{40} \mathrm{Ar}^{16} \mathrm{O}$ and ${ }^{40} \mathrm{Ar}^{14} \mathrm{~N}$ were minimised by sample desolvation where trifluoro-methane $\left(\mathrm{CHF}_{3}\right)$ is used as a supplementary gas and by using a Jet sampler cone and skimmer $\mathrm{H}$-cone in a MC-ICP-MS. The largest ${ }^{52} \mathrm{Cr}$ signal was monitored using a $10^{10} \Omega$ resistor to allow $>50 \mathrm{~V}$ beam intensities, while a $10^{12} \Omega$ variant was used for the small ${ }^{49} \mathrm{Ti}$ and ${ }^{56} \mathrm{Fe}$ signals. Results indicated that reproducibility was better than ${ }^{54} \mathrm{Cr} \pm 5.8 \times 10^{-6}$ although more sample was required than during traditional TIMS analysis.

Iron isotope compositions of minerals determined by laser ablation MC-ICP-MS was the focus of a study by d'Abzac et al. ${ }^{155}$ These workers captured particles of natural magnetite, siderite, pyrrhotite and pyrite induced by a femtosecond laser, for imaging and Fe isotope measurement by solution nebulisation. Results are particularly interesting as each mineral produced a different distribution of ${ }^{56} \mathrm{Fe}:{ }^{54} \mathrm{Fe}$ with respect to particle size. Larger particles generally had heavier-biased Fe than smaller, but mass difference/size distributions were found to be mineralspecific, e.g. pyrite showed much less laser-induced fractionation relative to magnetite. Differences between the mass fractionation behaviour of ablated mineral species is ascribed to the 
timing of element condensation in the laser-induced plasma: sulfur-bearing minerals such as pyrite restrict the early condensation of Fe and suppress Fe isotope fractionation.

The problem of measuring $\mathrm{Cu}$ and Fe isotope compositions on samples with low concentrations of these elements has been tackled by Costas-Rodriguez et al. ${ }^{156}$ Essentially a standard addition principle was used in mixing a known isotope ratio solution with the sample solution, both of known $\mathrm{Cu}$ concentration. Resulting mixed $\delta^{65} \mathrm{Cu}$ values for the sample agreed with the $\mathrm{Cu}$ isotope ratio determined by conventional bracketing techniques at higher sample concentration.

$\mathrm{Cu}$ and $\mathrm{Fe}$ isotopes were separated in a single-step chromatographic procedure by Liu et al. ${ }^{157}$ prior to MC-ICP-MS analysis. The authors documented a long-term reproducibility of better than $\pm 0.05 \%$ for both $\delta^{65} \mathrm{Cu}$ and $\delta^{56} \mathrm{Fe}$ and used the procedure to evaluate the $\mathrm{Fe}$ and $\mathrm{Cu}$ isotopic characteristics of igneous rock standards. Fe isotopes of these rocks were found to be relatively uniform whereas $\delta^{65} \mathrm{Cu}$ had a range of $0.4 \%$. This range extended from $\sim 0 \delta^{65} \mathrm{Cu}$ for BIR-1 (Icelandic basalt), through to +0.3 for BCR-2 (Colombia River basalt) and to +0.4 for GBW07122 (China amphibolite).

Petit et al. ${ }^{158}$ examined the effects of residual $\mathrm{Ti}$ and $\mathrm{Cr}$, remaining after anion-exchange separation, on MC-ICP-MS copper isotope measurement. Experiments showed that $\mathrm{Cu}$ and $\mathrm{Zn}$ isotope ratios were affected by synthetic and rock matrices which modified the amount and proportion of spectral interferences from $\mathrm{Ti}$ and $\mathrm{Cr}$ oxides and hydroxides. Their results indicated that $\mathrm{Cu}: \mathrm{Ti}: \mathrm{Cr}$ need to be equal to or lower than $1000: 10: 3$, following chromatography, to negate these effects.

High precision $\mathrm{Zn}$ isotope measurement in humans was the subject of a study by Larner et al. ${ }^{159}$ Blood samples were analysed to trace uptake of ${ }^{68} \mathrm{Zn}$ from $\mathrm{ZnO}$ nanoparticles in sunscreen. The results indicated that stable isotope labelling combined with MC-ICP-MS is a robust method for tracing metals in biological matrices.

Selenium isotopes in organic-rich shales were measured by Stueken et al. $^{\mathbf{1 6 0}}$ using MC-ICP-MS. Double spiking adjustment of mass fractionation is common practice for Se isotope systematics, but this study investigated a standard-sample bracketing correction. The advantages of bracketing were that five of the six Se isotopes could be determined, enabling a multiisotope examination of mass-independent fractionation and isobaric interference. A potential disadvantage of standardsample bracketing recognised by the authors was that the precision is slightly worse than double spiking. Additionally, as the bracketing technique requires a full recovery of selenium through chemistry, this study also recommended modifications to the digestion and chemical separation procedure.

Neymark et al. ${ }^{\mathbf{1 6 1}}$ documented the determination of stable strontium isotope variation in natural materials by TIMS. $\mathrm{A}^{207-}$ ${ }^{204} \mathrm{Sr}$ double spike corrected for chemical and instrumental mass fractionation, resulting in $\delta^{88: 86} \mathrm{Sr}$ reproducibility better than $0.02 \%$. Results from biogenic materials revealed the widest range in $\delta^{88: 86} \mathrm{Sr}$ recorded to date $(\sim 2.4 \%)$.

Mayer and Wieser ${ }^{\mathbf{1 6 2}}$ determined an absolute isotopic composition for molybdenum in an SRM. This was achieved by gravimetrically and instrumentally calibrating the absolute ratios of a ${ }^{92-98}$ Mo double spike. In turn, this spike was mixed with NIST SRM 3134 to determine all Mo isotope ratios and the atomic weight interval of this standard by MCICP-MS. Molybdenum isotope fractionation during chromatography has been examined by Malinovsky and Vanhaecke ${ }^{\mathbf{1 6 3}}$ with a view to assessing the potential for refining the purity of enriched isotope fractions. Anion exchange column separation of Mo solutions demonstrated a heavy Mo isotopic bias at the front of the absorption band during elution. However, the calculated column distance required to produce a workable enrichment in Mo isotopes - an increase from $98.2 \%$ to $99.9 \%$ was found to be $>400 \mathrm{~m}$. Results also indicated that all Mo isotopes behave in a mass-dependent manner during the chromatographic process.

Te is a rare element in the Earth's crust, but has a much higher cosmic abundance; hence studies of Te isotopics tend to concentrate on meteorites. Fukami and Yokoyama ${ }^{\mathbf{1 6 4}}$ presented a refined method for the chemical separation of Te and the determination of isotope ratios by TIMS. Around 250 $\mathrm{ng}$ of Te was ionised in analyses of standards, with detector normalisation completed using a multi-dynamic routine. Several meteorites and a terrestrial lava sample were measured to test the techniques, which demonstrated that $\delta$ Te was identical in all analyses. Fornadel et al. ${ }^{\mathbf{1 6 5}}$ have also investigated the chemical separation and isotope measurement of Te, this time using MC-ICP-MS. This study examined the stable isotope systematics of Te metal and tellurides in ores from Australia and USA using MC-ICP-MS. Around $1 \mu \mathrm{g}$ Te was aspirated in each analysis. Findings indicated that the Te isotopes across all of the samples studied had $\delta^{130: 125}$ Te in the range -1.0 to $0.6 \%( \pm 0.1 \%$ o $)$, with some individual mines spanning 0.5 delta units.

Isotope fractionation during column chemistry was tested by Miyazki et al. ${ }^{\mathbf{1 6 6}}$ who examined the possibility of high-precision stable isotope measurement of barium. These authors did not identify any Ba isotope fractionation on column recovery of $89 \%$ within the bounds of the measurement uncertainty $\left(\delta^{137: 134} \mathrm{Ba} \pm\right.$ $0.025 \%$ ). Mass dependent fractionation during MC-ICP-MS analysis was corrected using a ${ }^{130-135}$ Ba double spike and massindependent fractionation was accounted for by standardsample bracketing. The $\delta^{137: 134}$ Ba precision documented in this study is a factor of five better than achieved previously and was sufficient to identify differences between three igneous rock reference standards (JB-2, JA-2 and BHVO-2).

A new element to be assessed as a stable isotope tracer of natural processes is $\mathrm{Nd}$. Initial analytical methods for Nd stable isotope measurement by MC-ICP-MS without the use of double spiking have been presented by Ma et al. ${ }^{\mathbf{1 6 7}}$ Their work examined the chromatographic and instrumental pitfalls of $\mathrm{Nd}$ measurement; namely achieving maximum recovery during isolation and correcting for mass fractionation and isobaric interferences. Results indicated that standard-sample bracketing methodology produced errors on $\varepsilon^{146} \mathrm{Nd}$ and $\varepsilon^{148} \mathrm{Nd}$ of $<0.2$ and 0.5 respectively (2SD). Rock standards were found to have $\varepsilon^{146} \mathrm{Nd}$ ranging from -2.65 for a stream sediment (JSD-1) through to +2.12 for a granodiorite (JG-1a). 


\section{Abbreviations}

Whenever suitable, elements may be referred to by their chemical symbols and compounds by their formulae. The following abbreviations may be used without definition. Abbreviations also cover the plural form.

2D
3D
AA
AAS
AES
AF
AFS
AMS
ANN
BCR
CCD
CCP
CRM
CRS
CS
CV
CVG
DBD
DC
DLTV
DMA
DOTA

Two dimensional

Three dimensional

Atomic absorption

Atomic absorption spectrometry

Atomic emission spectrometry

Atomic fluorescence

Atomic fluorescence spectrometry

Accelerator mass spectrometry

Artificial neural network.

Community bureau of reference

Charge coupled detector

Capacitively coupled plasma

Certified reference material

Cavity ringdown spectroscopy

Continuum source

Cold vapour

Chemical vapour generation

Dielectric barrier discharge

Direct current

Diode laser thermal vaporisation

Dimethylarsinic (include oxidation state if known)

1,4,7,10-Tetraazacyclo-dodecane $N, N^{\prime}, N^{\prime \prime}, N^{\prime \prime \prime}$-tetra acetic acid

DPLA?

ES-MS

ETV

ETV-AAS

ETV-ICP-

MS

EVG

FHG

FID

FTS

GD

GD-MS

GF-AAS

HPLC-ICP-

MS

HR

ICP

ICP-AES

ICP-MS

ICP-OES

ICP-QMS

ICP-TOF- Inductively coupled plasma time-of-flight mass

MS

ID

IDA
Double-pulse laser ablation

Electrospray mass spectrometry

Electrothermal vaporisation

Electrothermal vaporisation atomic absorption spectrometry

Electrothermal vaporisation inductively coupled

plasma mass spectrometry

Electrochemical vapour generation

Fourth harmonic generator

Flame ionisation detection

Fourier transform spectrometry

Glow discharge

\section{Glow discharge mass spectrometry}

Graphite furnace atomic absorption spectrometry

High performance liquid chromatography

inductively coupled plasma mass spectrometry

High resolution

Inductively coupled plasma

Inductively coupled plasma atomic emission

spectrometry

Inductively coupled plasma mass spectrometry

Inductively coupled plasma optical emission

spectrometry

Inductively coupled plasma quadrupole mass

spectrometry

spectrometry

Isotope dilution

Isotope dilution analysis
ID-ICP-MS Isotope dilution inductively coupled plasma mass spectrometry

ID-MS Isotope dilution mass spectrometry

$\mathrm{iHg} \quad$ Inorganic mercury

IL Ionic liquid

IRMS Isotope ratio mass spectrometry

KED Kinetic energy distribution

LA Laser ablation

LA-ICP-MS Laser ablation inductively coupled plasma mass spectrometry

LA-MC-ICP- Laser ablation multi-collector inductively coupled MS plasma mass spectrometry

LAMIS Laser ablation molecular isotopic spectrometry

LA-SF-ICP- Laser ablation sector field inductively coupled

MS plasma mass spectrometry

LC Liquid chromatography

LDGD Liquid phase diaphragm glow discharge

LIBS Laser induced breakdown spectroscopy

LIF Laser induced fluorescence

LOD Limit of detection

LOV Lab-on-a-valve

MAS Molecular absorption spectroscopy

MC-ICP-MS Multi-collector inductively coupled plasma mass spectrometry

MeHg Methyl mercury

MIP Microwave induced plasma

MMA Monomethylarsenic

MNP Magnetic nanoparticle

Nd:YAG Neodymium doped:yttrium aluminum garnet

$n_{\mathrm{e}}$

NELIBS

NP

Od

OPA

PGM

PLS

PLSR

$\mathrm{PM}$

$\mathrm{ppb}$

ppm

ppq

ppt

PVG

$\mathrm{Q}$

QCL

$\mathrm{SF}$

SHS

SIMS

Sp

SPME

$T_{\mathrm{e}}$

$T_{\text {gas }}$

TIMS

$T_{\text {ion }}$

TOF

TP-LIF

TS

UV

VG
Electron number density

Nanoparticle enhanced LIBS

Nanoparticles

Outer diameter

Optical parametric amplifier

Platinum group metals

Partial least squares

Partial least squares regression

Permanent modifiers

Parts per billion $\left(10^{-9}\right)$

Parts per million $\left(10^{-6}\right)$

Parts per quadrillion $\left(10^{-15}\right)$

Parts per trillion $\left(10^{-12}\right)$

Photochemical vapour generation

Quadrupole

Quantum cascade laser

Sector field

Spatial heterodyne spectrometer

Secondary ion mass spectrometry

Single particle

Solid phase microextraction

Electron temperature

Gas temperature

Thermal ionization mass spectrometry

Ionisation temperature

Time-of-flight

Two photon laser induced fluorescence

Thomson scattering

Ultraviolet

Vapour generation 
VNIR Visible and near infrared reflectance VOC Volatile organic carbon

\section{References}

1 E. H. Evans, J. Pisonero, C. M. M. Smith and R. N. Taylor, J. Anal. At. Spectrom., 2014, 29(5), 773-794.

2 M. West, A. T. Ellis, P. J. Potts, C. Streli, C. Vanhoof and P. Wobrauschek, J. Anal. At. Spectrom., 2014, 29(9), 15161563.

3 R. Clough, C. F. Harrington, S. J. Hill, Y. Madrid and J. F. Tyson, J. Anal. At. Spectrom., 2014, 29(7), 1158-1196.

4 A. Taylor, M. P. Day, S. Hill, J. Marshall, M. Patriarca and M. White, J. Anal. At. Spectrom., 2014, 29(3), 386-426.

5 S. Carter, A. S. Fisher, M. W. Hinds, S. Lancaster and J. Marshall, J. Anal. At. Spectrom., 2013, 28(12), 1814-1869.

6 O. T. Butler, W. R. L. Cairns, J. M. Cook and C. M. Davidson, J. Anal. At. Spectrom., 2014, 29(1), 17-50.

7 T. S. Lum, Y. K. Tsoi and K. S. Y. Leung, J. Anal. At. Spectrom., 2014, 29(2), 234-241.

8 J. W. Deng, Y. Y. Yang, X. W. Wang and T. G. Luan, TrAC, Trends Anal. Chem., 2014, 55, 55-67.

9 C. K. Su, S. C. Hsia and Y. C. Sun, J. Chromatogr. A, 2014, 1326, 73-79.

10 C. K. Su, C. H. Yang, C. H. Lin and Y. C. Sun, Anal. Bioanal. Chem., 2014, 406(1), 239-247.

11 M. Wierucka and M. Biziuk, TrAC, Trends Anal. Chem., 2014, 59, 50-58.

12 E. Najafi, F. Aboufazeli, H. Zhad, O. Sadeghi and V. Amani, Food Chem., 2013, 141(4), 4040-4045.

13 E. M. Martinis, P. Berton and R. G. Wuilloud, TrAC, Trends Anal. Chem., 2014, 60, 54-70.

14 K. Bruckner, K. Schwarz, S. Beck and M. W. Linscheid, Anal. Chem., 2014, 86(1), 585-591.

15 Y. C. Luo, X. W. Yan, Y. S. Huang, R. B. Wen, Z. X. Li, L. M. Yang, C. J. Yang and Q. Q. Wang, Anal. Chem., 2013, 85(20), 9428-9432.

16 Y. He, D. L. Chen, M. X. Li, L. Fang, W. J. Yang, L. J. Xu and F. F. Fu, Biosens. Bioelectron., 2014, 58, 209-213.

17 L. Lopez-Fernandez, E. Blanco-Gonzalez and J. Bettmer, Analyst, 2014, 139(13), 3423-3428.

18 S. X. Zhang, G. J. Han, Z. Xing, S. C. Zhang and X. R. Zhang, Anal. Chem., 2014, 86(7), 3541-3547.

19 T. C. de Bang, P. Shah, S. K. Cho, S. W. Yang and S. Husted, Anal. Chem., 2014, 86(14), 6823-6826.

20 G. Schwarz, L. Mueller, S. Beck and M. W. Linscheid, J. Anal. At. Spectrom., 2014, 29(2), 221-233.

21 Y. He, Y. Y. Zhang, C. Wei, C. Y. Li, Y. Gao and R. Liu, Appl. Spectrosc. Rev., 2014, 49(6), 492-512.

22 B. Campanella and E. Bramanti, Analyst, 2014, 139(17), 4124-4153.

23 T. Konz, M. Montes-Bayon and A. Sanz-Medel, Analyst, 2014, 139(21), 5451-5459.

24 T. Konz, E. A. Alvarez, M. Montes-Bayon and A. Sanz-Medel, Anal. Chem., 2013, 85(17), 8334-8340.
25 Y. Liang, X. W. Yan, Z. X. Li, L. M. Yang, B. Zhang and Q. Q. Wang, Anal. Chem., 2014, 86(8), 3688-3692.

$26 \mathrm{~A}$. H. El-Khatib, D. Esteban-Fernandez and M. W. Linscheid, Anal. Chem., 2014, 86(4), 1943-1948.

27 X. W. Yan, Z. X. Li, Y. Liang, L. M. Yang, B. Zhang and Q. Q. Wang, Chem. Commun., 2014, 50(50), 6578-6581.

28 R. Liu, P. Wu, L. Yang, X. D. Hou and Y. Lv, Mass Spectrom. Rev., 2014, 33(5), 373-393.

29 Z. B. Bjornson, G. P. Nolan and W. J. Fantl, Curr. Opin. Immunol., 2013, 25(4), 484-494.

30 H. Y. Peng, Y. Jiao, X. Xiao, B. B. Chen, M. He, Z. R. Liu, X. Zhang and B. Hu, J. Anal. At. Spectrom., 2014, 29(6), 1112-1119.

31 Y. Zhang, B. B. Chen, M. He, B. Yang, J. Zhang and B. Hu, Anal. Chem., 2014, 86(16), 8082-8089.

32 L. Mueller, T. Mairinger, G. Hermann, G. Koellensperger and S. Hann, Anal. Bioanal. Chem., 2014, 406(1), 163-169.

33 Q. He, Z. L. Zhu, L. L. Jin, L. Peng, W. Guo and S. H. Hu, J. Anal. At. Spectrom., 2014, 29(8), 1477-1482.

34 L. Waentig, S. Techritz, N. Jakubowski and P. H. Roos, Analyst, 2013, 138(21), 6309-6315.

35 A. Elias, S. H. Crayton, R. Warden-Rothman and A. Tsourkas, Sci. Rep., 2014, 4, 9.

36 J. Ko and H. B. Lim, Anal. Chem., 2014, 86(9), 4140-4144.

37 P. E. Verboket, O. Borovinskaya, N. Meyer, D. Gunther and P. S. Dittrich, Anal. Chem., 2014, 86(12), 6012-6018.

38 F. Laborda, E. Bolea and J. Jimenez-Lamana, Anal. Chem., 2014, 86(5), 2270-2278.

39 T. P. J. Linsinger, R. Peters and S. Weigel, Anal. Bioanal. Chem., 2014, 406(16), 3835-3843.

40 J. Y. Liu, K. E. Murphy, R. I. MacCuspie and M. R. Winchester, Anal. Chem., 2014, 86(7), 3405-3414.

41 A. Hineman and C. Stephan, J. Anal. At. Spectrom., 2014, 29(7), 1252-1257.

42 J. Tuoriniemi, G. Cornelis and M. Hassellov, J. Anal. At. Spectrom., 2014, 29(4), 743-752.

43 P. Pohl, P. Jamroz, M. Welna, A. Szymczycha-Madeja and K. Greda, TrAC, Trends Anal. Chem., 2014, 59, 144-155.

44 M. Slachcinski, Appl. Spectrosc. Rev., 2014, 49(4), 271-321.

45 A. Lopez-Molinero, D. Sipiera and J. R. Castillo, J. Anal. At. Spectrom., 2014, 29(1), 111-121.

46 M. A. Reddy, R. Shekhar and S. J. Kumar, At. Spectrosc., 2013, 34(4), 119-124.

47 A. D. Sun, Q. C. Xu, S. J. Xu, X. H. Shangguan, H. Y. Shen and J. Sun, Anal. Lett., 2013, 46(16), 2610-2619.

48 L. Rastogi, M. V. B. Krishna, K. Chandrasekaran and D. Karunasagar, J. Anal. At. Spectrom., 2014, 29(4), 721-729.

49 M. Yang, J. Xue, M. Li, G. J. Han, Z. Xing, S. C. Zhang and X. R. Zhang, Talanta, 2014, 126, 1-7.

50 T. T. Shih, C. H. Lin, I. H. Hsu, J. Y. Chen and Y. C. Sun, Anal. Chem., 2013, 85(21), 10091-10098.

51 W. L. Yang, Y. Gao, L. Wu, X. D. Hou, C. B. Zheng and X. F. Zhu, Microchim. Acta, 2014, 181(1-2), 197-204.

52 M. Huang, W. E. Gan and S. S. Xie, Anal. Methods, 2014, 6(6), 1796-1801.

53 A. R. Borges, L. L. Francois, B. Welz, E. Carasek and M. G. R. Vale, J. Anal. At. Spectrom., 2014, 29(9), 1564-1569. 
54 I. N. B. Castilho, E. R. Pereira, B. Welz, A. A. Shaltout, E. Caraseka and I. B. G. Martensd, Anal. Methods, 2014, 6(9), 2870-2875.

55 F. V. Nakadi, L. R. Rosa and M. da Veiga, Spectrochim. Acta, Part B, 2013, 88, 80-84.

56 Y. J. Liu and L. r. Wang, Spectrosc. Spectral Anal., 2013, 33(9), 2570-2573.

57 Y. J. Liu, B. Sun and L. Wang, Anal. Lett., 2014, 47(8), 14091420.

58 R. L. Vander Wal, C. K. Gaddam and M. J. Kulis, Appl. Spectrosc., 2014, 68(6), 649-656.

59 R. L. Vander Wal, C. K. Gaddam and M. J. Kulis, J. Anal. At. Spectrom., 2014, 29(10), 1791-1798.

60 A. L. Faure, C. Rodriguez, O. Marie, J. Aupiais and F. Pointurier, J. Anal. At. Spectrom., 2014, 29(1), 145-151.

61 J. R. Chirinos, D. D. Oropeza, J. J. Gonzalez, H. M. Hou, M. Morey, V. Zorba and R. E. Russo, J. Anal. At. Spectrom., 2014, 29(7), 1292-1298.

62 J. S. Becker, A. Matusch and B. Wu, Anal. Chim. Acta, 2014, 835, 1-18.

63 F. Blaske, O. Reifschneider, G. Gosheger, C. A. Wehe, M. Sperling, U. Karst, G. Hauschild and S. Holl, Anal. Chem., 2014, 86(1), 615-620.

64 M. Bonta, H. Lohninger, M. Marchetti-Deschmann and A. Limbeck, Analyst, 2014, 139(6), 1521-1531.

65 S. Hoesl, B. Neumann, S. Techritz, M. Linscheid, F. Theuring, C. Scheler, N. Jakubowski and L. Mueller, $J$. Anal. At. Spectrom., 2014, 29(7), 1282-1291.

66 H. A. O. Wang, D. Grolimund, C. Giesen, C. N. Borca, J. R. H. Shaw-Stewart, B. Bodenmiller and D. Gunther, Anal. Chem., 2013, 85(21), 10107-10116.

67 O. S. Ovchinnikova, M. Lorenz, V. Kertesz and G. J. Van Berkel, Anal. Chem., 2013, 85(21), 10211-10217.

68 P. Foltynova, A. Bednarik, V. Kanicky and J. Preisler, J. Anal. At. Spectrom., 2014, 29(9), 1585-1590.

69 F. Y. Meng, X. Yuan, X. M. Li, Y. Liu and Y. X. Duan, Appl. Spectrosc. Rev., 2014, 49(7), 533-549.

70 B. J. Han, X. M. Jiang, X. D. Hou and C. B. Zheng, Anal. Chem., 2014, 86(1), 936-942.

71 T. Krahling, A. Michels, S. Geisler, S. Florek and J. Franzke, Anal. Chem., 2014, 86(12), 5822-5828.

72 T. Shirafuji, Y. Ogura and Y. Himeno, Jpn. J. Appl. Phys., 2014, 53(1), 6.

73 A. Riedo, S. Meyer, B. Heredia, M. B. Neuland, A. Bieler, M. Tulej, I. Leya, M. Iakovleva, K. Mezger and P. Wurz, Planet. Space Sci., 2013, 87, 1-13.

74 J. E. Lawler, A. J. Fittante and E. A. Den Hartog, J. Phys. B: At., Mol. Opt. Phys., 2013, 46(21), 15.

75 G. Acharyulu, M. Sankari, P. V. K. Kumar and M. V. Suryanarayana, J. Quant. Spectrosc. Radiat. Transfer, 2014, 133, 251-263.

76 D. E. Shelby, S. Merk, B. W. Smith, I. B. Gornushkin, U. Panne and N. Omenetto, Spectrochim. Acta, Part B, 2013, 89, 50-59.

77 Z. Weiss, E. B. M. Steers, J. C. Pickering and S. Mushtaq, Spectrochim. Acta, Part B, 2014, 92, 70-83.
78 C. Yubero, M. C. Garcia, M. Varo and P. Martinez, Spectrochim. Acta, Part B, 2013, 90, 61-67.

79 O. Borovinskaya, M. Aghaei, L. Flamigni, B. Hattendorf, M. Tanner, A. Bogaerts and D. Gunther, J. Anal. At. Spectrom., 2014, 29(2), 262-271.

80 M. Aghaei, L. Flamigni, H. Lindner, D. Gunther and A. Bogaerts, J. Anal. At. Spectrom., 2014, 29(2), 249-261.

81 J. T. Shelley, A. Stindt, J. Riedel and C. Engelhard, J. Anal. At. Spectrom., 2014, 29(2), 359-366.

82 V. Horvatic, S. Muller, D. Veza, C. Vadla and J. Franzke, J. Anal. At. Spectrom., 2014, 29(3), 498-505.

83 S. K. Gupta, S. K. Thulasidas, P. J. Purohit, N. Goyal and S. V. Godbole, At. Spectrosc., 2013, 34(6), 228-237.

84 Y. V. Rogulsky, V. Y. Illiashenko and A. N. Kulik, J. Appl. Spectrosc., 2014, 80(6), 917-921.

85 M. Y. Burylin and Z. A. Temerdashev, Inorg. Mater., 2013, 49(14), 1264-1271.

86 D. J. Butcher, Anal. Chim. Acta, 2013, 804, 1-15.

87 N. Taylor, K. N. McKay-Bishop, R. L. Spencer and P. B. Farnsworth, J. Anal. At. Spectrom., 2014, 29(4), 644-656.

88 T. Nakazawa, D. Suzuki, H. Sakuma and N. Furuta, J. Anal. At. Spectrom., 2014, 29(7), 1299-1305.

89 K. Boting, S. Treu, P. Leonhard, C. Heiss and N. H. Bings, J. Anal. At. Spectrom., 2014, 29(3), 578-582.

90 K. Chiba and T. Narukawa, Anal. Sci., 2014, 30(1), 175-181. 91 E. Bolea-Fernandez, L. Balcaen, M. Resano and F. Vanhaecke, Anal. Chem., 2014, 86(15), 7969-7977.

92 J. Carlson, A. Wysoczanski and E. Voigtman, Spectrochim. Acta, Part B, 2014, 96, 69-73.

93 S. Buckley, Spectroscopy, 2014, 29(1), 22-29.

94 S. Buckley, Spectroscopy, 2014, 29(4), 26-31.

95 S. Buckley, Spectroscopy, 2014, 29(10), 24-30.

96 K. H. Kurniawan, M. O. Tjia and K. r. Kagawa, Appl. Spectrosc. Rev., 2014, 49(5), 323-434.

97 V. Spizzichino and R. Fantoni, Spectrochim. Acta, Part B, 2014, 99, 201-209.

98 X. H. Wang, S. D. Zhang, X. L. Cheng, E. Y. Zhu, W. Hang and B. L. Huang, Spectrochim. Acta, Part B, 2014, 99, 101114.

99 K. Dzierzega, A. Mendys and B. Pokrzywka, Spectrochim. Acta, Part B, 2014, 98, 76-86.

100 F. O. Borges, G. H. Cavalcanti, G. C. Gomes, V. Palleschi and A. Mello, Appl. Phys. B: Lasers Opt., 2014, 117(1), 437-444.

101 X. H. Li, B. W. Smith and N. Omenetto, J. Anal. At. Spectrom., 2014, 29(4), 657-664.

102 I. B. Gornushkin, B. W. Smith, U. Panne and N. Omenetto, Appl. Spectrosc., 2014, 68(9), 1076-1084.

103 A. De Giacomo, R. Gaudiuso, C. Koral, M. Dell'Aglio and O. De Pascale, Spectrochim. Acta, Part B, 2014, 98, 19-27.

104 M. Tampo, M. Miyabe, K. Akaoka, M. Oba, H. Ohba, Y. Maruyama and I. Wakaida, J. Anal. At. Spectrom., 2014, 29(5), 886-892.

105 L. Liu, S. Li, X. N. He, X. Huang, C. F. Zhang, L. S. Fan, M. X. Wang, Y. S. Zhou, K. Chen, L. Jiang, J. F. Silvain and Y. F. Lu, Opt. Express, 2014, 22(7), 7686-7693.

106 C. Álvarez, J. Pisonero and N. Bordel, Spectrochim. Acta, Part $B, 2014,100,123-128$. 
107 X. B. Zhang, Y. Deguchi, Z. Z. Wang, J. J. Yan and J. P. Liu, J. Anal. At. Spectrom., 2014, 29(6), 1082-1089.

108 C. Beresko, P. Kohns and G. Ankerhold, Spectrochim. Acta, Part B, 2014, 99, 20-27.

109 S. P. Banerjee and R. Fedosejevs, Spectrochim. Acta, Part B, 2014, 92, 34-41.

110 R. Glaus and D. W. Hahn, Spectrochim. Acta, Part B, 2014, 98, 48-53.

111 E. D'Andrea, S. Pagnotta, E. Grifoni, G. Lorenzetti, S. Legnaioli, V. Palleschi and B. Lazzerini, Spectrochim. Acta, Part B, 2014, 99, 52-58.

112 A. Sarkar, X. L. Mao and R. E. Russo, Spectrochim. Acta, Part $B, 2014,92,42-50$.

113 H. M. Hou, Y. Tian, Y. Li and R. Zheng, J. Anal. At. Spectrom., 2014, 29(1), 169-175.

114 M. Lawrence-Snyder, J. P. Scaffidi, W. F. Pearman, C. M. Gordon and S. M. Angel, Spectrochim. Acta, Part B, 2014, 99, 172-178.

115 L. Z. Zhang, G. Tian, J. S. Li and B. L. Yu, Appl. Spectrosc., 2014, 68(10), 1095-1107.

116 G. Bostrom, A. Rice and D. Atkinson, Opt. Lett., 2014, 39(14), 4227-4230.

117 H. Berberoglu and H. Altan, Opt. Commun., 2014, 317, 2933.

118 W. D. Kulatilaka, J. R. Gord and S. Roy, Appl. Phys. B: Lasers Opt., 2014, 116(1), 7-13.

119 A. Gourgiotis, S. Berail, P. Louvat, H. Isnard, J. Moureau, A. Nonell, G. Manhes, J. L. Birck, J. Gaillardet, C. Pecheyran, F. Chartier and O. F. X. Donard, J. Anal. At. Spectrom., 2014, 29(9), 1607-1617.

120 J. M. Koornneef, C. Bouman, J. B. Schwieters and G. R. Davies, Anal. Chim. Acta, 2014, 819(0), 49-55.

121 T. J. Ireland, F. L. H. Tissot, R. Yokochi and N. Dauphas, Chem. Geol., 2013, 357, 203-214.

122 W. Kutschera, Int. J. Mass Spectrom., 2013, 349, 203-218.

123 H.-A. Synal, Int. J. Mass Spectrom., 2013, 349-350(0), 192202.

124 K. J. Dong, C. Wang, M. He, D. Y. Lin, X. H. Zhao, L. L. Li, Y. G. Zhao, L. Dou, L. B. Xie, S. Y. Wu, X. Y. Yin, X. G. Wang, H. T. Shen, Q. B. You and S. Jiang, Chin. Phys. Lett., 2014, 31(1), 3 .

125 M. Christl, X. X. Dai, J. Lachner, S. Kramer-Tremblay and H. A. Synal, Nucl. Instrum. Methods Phys. Res., Sect. B, 2014, 331, 225-232.

126 X. G. Wang, S. Jiang, M. He, K. J. Dong, H. T. Chen, G. Z. He, W. Wang, S. Y. Wu and Y. M. Hu, Radiocarbon, 2013, 55(23), 294-301.

127 J. Zheng, W. T. Bu, K. Tagami, Y. Shikamori, K. Nakano, S. Uchida and N. Ishii, Anal. Chem., 2014, 86(14), 71037110 .

128 Z. Ezerinskis, A. Spolaor, T. Kirchgeorg, G. Cozzi, P. Vallelonga, H. A. Kjaer, J. Sapolaite, C. Barbante and R. Druteikiene, J. Anal. At. Spectrom., 2014, 29(10), 18271834.

129 A. Hubert, F. Claverie, C. Pecheyran and F. Pointurier, Spectrochim. Acta, Part B, 2014, 93, 52-60.
130 Y. Miyamoto, F. Esaka, D. Suzuki and M. Magara, Radiochim. Acta, 2013, 101(11), 745-748.

131 A. Quemet, M. Maloubier, V. Dalier and A. Ruas, Int. J. Mass Spectrom., 2014, 374(0), 26-32.

132 Y. A. Uvarova, T. K. Kyser, M. L. Geagea and D. Chipley, Geochim. Cosmochim. Acta, 2014, 146(0), 1-17.

133 M. J. Murphy, C. H. Stirling, A. Kaltenbach, S. P. Turner and B. F. Schaefer, Earth Planet. Sci. Lett., 2014, 388(0), 306-317.

134 N. M. McLean, Geochim. Cosmochim. Acta, 2014, 124, 237249.

135 R. N. Taylor, O. Ishizuka, A. Michalik, J. A. Milton and I. W. Croudace, J. Anal. At. Spectrom., 2015, 30(1), 198-213.

136 M. Dronov and J. Schram, J. Anal. At. Spectrom., 2013, 28(11), 1796-1803.

137 D. M. Chew, J. A. Petrus and B. S. Kamber, Chem. Geol., 2014, 363, 185-199.

138 C. S. Cheong, J. S. Ryu and Y. J. Jeong, Geosci. J., 2013, 17(4), 389-395.

139 K. C. Crocket, M. Lambelet, T. V. de Flierdt, M. Rehkamper and L. F. Robinson, Chem. Geol., 2014, 374, 128-140.

140 J. G. Konter and L. P. Storm, Chem. Geol., 2014, 385(0), 2634.

141 J. G. Liu and D. G. Pearson, Chem. Geol., 2014, 363, 301-311. 142 J. M. Eiler, B. Bergquist, I. Bourg, P. Cartigny, J. Farquhar, A. Gagnon, W. F. Guo, I. Halevy, A. Hofmann, T. E. Larson, N. Levin, E. A. Schauble and D. Stolper, Chem. Geol., 2014, 372, 119-143.

143 G. L. Foster, B. Honisch, G. Paris, G. S. Dwyer, J. W. B. Rae, T. Elliott, J. Gaillardet, N. G. Hemming, P. Louvat and A. Vengosh, Chem. Geol., 2013, 358, 1-14.

144 P. Louvat, J. Moureau, G. Paris, J. Bouchez, J. Noireaux and J. Gaillardet, J. Anal. At. Spectrom., 2014, 29(9), 1698-1707.

145 J. L. Pi, C. F. You and C. H. Chung, J. Anal. At. Spectrom., 2014, 29(5), 861-867.

146 E. S. F. Berman, N. E. Levin, A. Landais, S. N. Li and T. Owano, Anal. Chem., 2013, 85(21), 10392-10398.

147 T. Wu, W. D. Chen, E. Fertein, P. Masselin, X. M. Gao, W. J. Zhang, Y. J. Wang, J. Koeth, D. Bruckner and X. D. He, Sensors, 2014, 14(5), 9027-9045.

148 Y. J. An and F. Huang, J. Earth Sci., 2014, 25(5), 822-840.

149 W. A. Brand, T. B. Coplen, J. Vogl, M. Rosner and T. Prohaska, Pure Appl. Chem., 2014, 86(3), 425-467.

150 F. Z. Teng and W. Yang, Rapid Commun. Mass Spectrom., 2014, 28(1), 19-24.

151 A. J. Lin, T. Yang and S. Y. Jiang, Rapid Commun. Mass Spectrom., 2014, 28(7), 750-756.

152 G. O. Lehn, A. D. Jacobson and C. Holmden, Int. J. Mass Spectrom., 2013, 351, 69-75.

153 M. A. Millet and N. Dauphas, J. Anal. At. Spectrom., 2014, 29(8), 1444-1458.

154 M. Schiller, E. Van Kooten, J. C. Holst, M. B. Olsen and M. Bizzarro, J. Anal. At. Spectrom., 2014, 29(8), 1406-1416.

155 F. X. d'Abzac, B. L. Beard, A. D. Czaja, H. Konishi, J. J. Schauer and C. M. Johnson, Anal. Chem., 2013, 85(24), 11885-11892.

156 M. Costas-Rodriguez, L. Lobo and F. Vanhaecke, Anal. Bioanal. Chem., 2014, 406(18), 4393-4399. 
157 S. A. Liu, D. D. Li, S. G. Li, F. Z. Teng, S. Ke, Y. S. He and Y. H. Lu, J. Anal. At. Spectrom., 2014, 29(1), 122-133.

158 J. C. J. Petit, A. Taillez and N. Mattielli, Geostand. Geoanal. Res., 2013, 37(3), 319-335.

159 F. Larner, B. Gulson, M. McCall, Y. Oytam and M. Rehkamper, J. Anal. At. Spectrom., 2014, 29(3), 471-477. 160 E. E. Stueken, J. Foriel, B. K. Nelson, R. Buick and D. C. Catling, J. Anal. At. Spectrom., 2013, 28(11), 1734-1749. 161 L. A. Neymark, W. R. Premo, N. N. Mel'nikov and P. Emsbo, J. Anal. At. Spectrom., 2014, 29(1), 65-75.

162 A. J. Mayer and M. E. Wieser, J. Anal. At. Spectrom., 2014, 29(1), 85-94.
163 D. Malinovsky and F. Vanhaecke, J. Anal. At. Spectrom., 2014, 29(6), 1090-1097.

164 Y. Fukami and T. Yokoyama, J. Anal. At. Spectrom., 2014, 29(3), 520-528.

165 A. P. Fornadel, P. G. Spry, S. E. Jackson, R. D. Mathur, J. B. Chapman and I. Girard, J. Anal. At. Spectrom., 2014, 29(4), 623-637.

166 T. Miyazaki, J. I. Kimura and Q. Chang, J. Anal. At. Spectrom., 2014, 29(3), 483-490.

167 J. L. Ma, G. J. Wei, Y. Liu, Z. Y. Ren, Y. G. Xu and Y. H. Yang, J. Anal. At. Spectrom., 2013, 28(12), 1926-1931. 